Article

\title{
Applicability of Different Double-Layer Models for the Performance Assessment of the Capacitive Energy Extraction Based on Double Layer Expansion (CDLE) Technique
}

\author{
Zhi Zou ${ }^{1}$, Longcheng Liu ${ }^{1,2}$, Shuo Meng ${ }^{2}$, Xiaolei Bian ${ }^{1}$ (D) and Yongmei Li ${ }^{3, *}$ \\ 1 Department of Chemical Engineering and Technology, Royal Institute of Technology, \\ 10044 Stockholm, Sweden; zhizou@kth.se (Z.Z.); lliu@ket.kth.se (L.L.); xiaoleib@kth.se (X.B.) \\ 2 School of Nuclear Science and Technology, University of South China, Hengyang 421001, China; \\ shuom@usc.edu.cn \\ 3 School of Resource \& Environment and Safety Engineering, University of South China, \\ Hengyang 421001, China \\ * Correspondence: lymusa8866@163.com
}

Citation: Zou, Z.; Liu, L.; Meng, S.; Bian, X.; Li, Y. Applicability of Different Double-Layer Models for the Performance Assessment of the Capacitive Energy Extraction Based on Double Layer Expansion (CDLE) Technique. Energies 2021, 14, 5828. https://doi.org/10.3390/en14185828

Academic Editor: Marcin Kamiński

Received: 16 August 2021

Accepted: 12 September 2021

Published: 15 September 2021

Publisher's Note: MDPI stays neutral with regard to jurisdictional claims in published maps and institutional affiliations.

Copyright: (c) 2021 by the authors. Licensee MDPI, Basel, Switzerland. This article is an open access article distributed under the terms and conditions of the Creative Commons Attribution (CC BY) license (https:// creativecommons.org/licenses/by/ $4.0 /)$.

\begin{abstract}
Capacitive energy extraction based on double layer expansion (CDLE) is a renewable method of harvesting energy from the salinity difference between seawater and freshwater. It is based on the change in properties of the electric double layer (EDL) formed at the electrode surface when the concentration of the solution is changed. Many theoretical models have been developed to describe the structural and thermodynamic properties of the EDL at equilibrium, e.g., the Gouy-ChapmanStern (GCS), Modified Poisson-Boltzmann-Stern (MPBS), modified Donnan (mD) and improved modified Donnan (i-mD) models. To evaluate the applicability of these models, especially the rationality and the physical interpretation of the parameters that were used in these models, a series of single-pass and full-cycle experiments were performed. The experimental results were compared with the numerical simulations of different EDL models. The analysis suggested that, with optimized parameters, all the EDL models we examined can well explain the equilibrium charge-voltage relation of the single-pass experiment. The GCS and MPBS models involve, however, the use of physically unreasonable parameter values. By comparison, the i-mD model is the most recommended one because of its accuracy in the results and the meaning of the parameters. Nonetheless, the i-mD model alone failed to simulate the energy production of the full-cycle CDLE experiments. Future research regarding the $\mathrm{i}-\mathrm{mD}$ model is required to understand the process of the CDLE technique better.
\end{abstract}

Keywords: CapMix; CDLE; electric double layer; salinity difference energy; modified Donnan

\section{Introduction}

The rapid economic development has led to increasingly serious conflict between resources and the environment, which forced the world to search for sustainable and green energy to substitute traditional energy [1-3]. One promising and reliable opinion is to extract energy from the salinity difference between seawater and freshwater. It is based firmly on the fact that when two solutions with different salinity are mixed, the entropy of the system will increase, which can be captured and converted into electrical energy [4]. Theoretically, about $2.5 \mathrm{MJ}$ of free energy could be generated by controlled mixing of $1 \mathrm{~m}^{3}$ river water with a large amount of seawater. The global potential for energy extraction from the world coast would, then, reach 2 TW of power, which satisfies around $20 \%$ of the world's energy demand [5,6].

By considering the tremendous amount of energy available from salinity difference, some techniques were proposed to harvest this energy. The pressure-retarded osmosis (PRO) [7,8] and reverse electrodialysis (RED) [9] are two advanced techniques and have been demonstrated at a pilot scale $[7,10]$. In $\mathrm{PRO}$, the seawater and freshwater are separated by a semi-permeable membrane, which drives water from the freshwater to permeate 
into the more concentrated seawater due to the difference in osmotic pressure. The expanding volume of the seawater can be depressurized through a hydroturbine to generate electricity. In RED, the solutions with different salt concentrations flow alternately in compartments, which are separated by a stack of positively and negatively charged ionexchange membrane. The ion diffusion across the membranes generates a current that can be extracted $[10,11]$. Up to now, the highest reported power density for PRO and RED are around 10 and $1 \mathrm{~W} / \mathrm{m}^{2}$, respectively [12]. Although significant progress has been made in both PRO and RED, the drawbacks of these techniques are also obvious, including the high cost and short lifetime of membranes, as well as the use of additional converters (hydroturbine in PRO) for effectively producing electricity. These drawbacks hampered the commercialization of both PRO and RED techniques and drive researchers to develop new technologies, such as Capacitive mixing (CapMix).

The so-called CapMix is an innovative technology that was recently introduced for extracting energy from salinity differences. It is the common name for several electrodebased technologies [13-16], including Capacitive energy extraction based on Double Layer Expansion (CDLE), Capacitive energy extraction based on Donnan Potential (CDP) and Soft Electrode technique (SE). In CDLE, the porous electrodes are first charged in salty water by an external power source and then discharged in fresh water; this process leads to an electrical double layer (EDL) expansion and results in an increase in electric potential. In CDP, the porous electrodes are covered by ion-exchange membranes, which only allow anion or cation to pass through and thus generates a Donnan potential difference across the membrane. In the SE technique, instead of using membranes in CDP, the electrodes are made of an activated carbon core together with a polyelectrolyte layer, either cationic or anionic. The major disadvantage of CapMix is the intermittent power production as well as the low power density, and the largest reported power density for CDLE, CDP and SE are 35,105 and $50 \mathrm{~mW} / \mathrm{m}^{2}$, respectively.

Among the techniques of the CapMix family, CDLE is the earliest technique that was first proposed and implemented experimentally by Brogioli [13] in 2009. It is the simplest one in terms of structure, composed of two electrodes that are parallel to each other and a spacer serving as a channel for water flowing through the cell without the use of ion-exchange membranes. The performance of the CDLE technique is dependent on the properties of the electrodes, cell structure as well as operation method. In the study of material properties, Iglesias et al. [17] investigated the effect of carbon wettability and pore size distribution on the performance of CDLE and found that electrodes with hydrophilized material improve the energy production of CDLE. They also concluded that activated carbon with a predominant pore population in the $1 \mathrm{~nm}$ region gives an optimum result. In another study about the effects of pore sizes of the porous electrode, Nasir et al. [18] also suggested that the optimum average pore diameter of electrodes for CDLE is about $1 \mathrm{~nm}$. Furthermore, Iglesias et al. [19] investigated the possibility of stacking individual CDLE cells in series to increase energy production. They found that multiple cells in series might increase the potential rise and that such an increase is limited and cannot compensate for the increase in internal resistance. The influence of the operation conditions, such as the flow velocity and the solution temperature, on the performance of CDLE, was also investigated. It was reported that a higher flow rate might lead to an improvement in the power production of CDLE [18] and that by controlled mixing solutions with different temperatures, the potential rise can be maximized, and thus the energy production can be increased [20].

By following experimental works, theoretical studies were also conducted over the years to provide a platform for identifying the influences of different parameters on the CDLE process. The theoretical models in CDLE focus mainly on the description of thermodynamic properties of EDL as well as the transport of ions inside the porous electrode. Among different equilibrium models, the Gouy-Chapman-Stern (GCS) model has been widely used to simulate the thermodynamic CDLE cycle [18,21-23]. This model is simple but does not account for the effects of EDL overlap and the finite size of the ions. To 
remedy this problem, Jiménez et al. [24] developed a modified Possion-Boltzmann-Stern (MPBS) model and applied it to predict the maximum energy production of CDLE. It was also extended to consider the influences of multi-ionic solutions and cylindrical pores, suggesting that the presence of multivalent ions would reduce the net energy gain in a CDLE cycle [25].

The model for the description of EDL at equilibrium alone cannot be applied to describe the dynamic behavior of CDLE cells. It should, in principle, be coupled with ionic and current transport models to give a fully quantitative description of the complex mechanisms affecting the performance of the CDLE as performed by Rica et al. [26,27]. The dynamic model originally proposed by Rica et al. [27] was based on a 1D theory that was developed by Biesheuvel and Bazant [28] with the use of the GCS model. It was later found that by using a modified Donnan $(\mathrm{mD})$ model instead, the kinetics of ionic transport and adsorption in the CDLE could be better described in the cases where the EDLs are overlapped within the micropores of the electrodes.

For whatever purpose, an accurate description of the structural and the thermodynamic properties of the EDL at equilibrium is essential in understanding the behavior of CDLE cells. In the literature, however, the use of different EDL models in the study of CDLE is somehow arbitrary without giving a detailed discussion on the applicability of the models, especially the rationality and the physical interpretation of the relevant parameters contained in the models, even though these models have been successfully applied in many works $[19,22,23]$. However, the physical meaning behind the parameters is important for better understand the thermodynamic properties of the EDLs. Mainly, for this reason, we strive to highlight the physical differences between some commonly used EDL models and then evaluate the applicability of different EDL models for the performance assessment of the CDLE technique.

The remainder of this contribution is organized as follows. In the next section, a brief description is provided of the experiment setup and the operation scheme. Then, a detailed elaboration of different EDL models is made in Section 3. The comparison between the experimental results with the simulations of different EDL models is then presented in Section 4 , followed by physical interpretations of the parameters used in the models and a discussion on the models' applicability. The contribution ends with concluding remarks.

\section{Materials and Methods}

In order to investigate the performance of the CDLE cells and also explore the applicability of different EDL models in the description of CDLE behaviors, a series of experiments were made using the setup shown in Figure 1.

\subsection{Materials}

The slurry of activated carbon was made by mixing commercial activated carbon power (YP-50F, Kuraray Chemical Company, Tokyo, Japan) with a polyvinylidene fluoride binder (Kynar HSV 900 PVDF, Arkema, France) at a ratio of 90:10 wt\%. The mixture was dispersed in N-methylpyrrolidone (NMP, 99\%, Sigma Aldrich, Milwaukee WI, USA) and was stirred for $12 \mathrm{~h}$ to form a homogeneous slurry. It was then cast on a titanium plate and dried in an oven at $80^{\circ} \mathrm{C}$ for $2 \mathrm{~h}$ to form the carbon sheet electrode. Each electrode had a size of $30 \mathrm{~mm} \times 60 \mathrm{~mm}$ and a total weight of about $0.08 \mathrm{~g}$.

The structure of raw activated carbon and the fabricated electrode was both determined by the nitrogen adsorption/desorption isotherm (Micromeritics ASAP 2000) that was based on the Brunauer-Emmett-Teller (BET) method. The average pore diameter and pore volume were estimated by the Barrett-Joyner-Halenda (BJH) method and t-plot method, respectively. The experimental results are listed in Table 1; note that the pore thickness $\left(H_{p}\right)$ is defined as the ratio of the micropores' volume $\left(V_{\text {micro }}\right)$ to the microporous area $\left(S_{\text {micro }}\right)$ [28]. As seen in Table 1 , there are reductions in some structural parameters of the fabricated electrode (including the specific surface area, micropore surface area, total volume and micropore volume) compared to the same parameters of raw activated 
carbon. The reason for this may be attributed to the PVDF binder in the fabricated electrode. Nevertheless, there is not much difference in the average pore diameter between activated carbon and fabricated electrode.

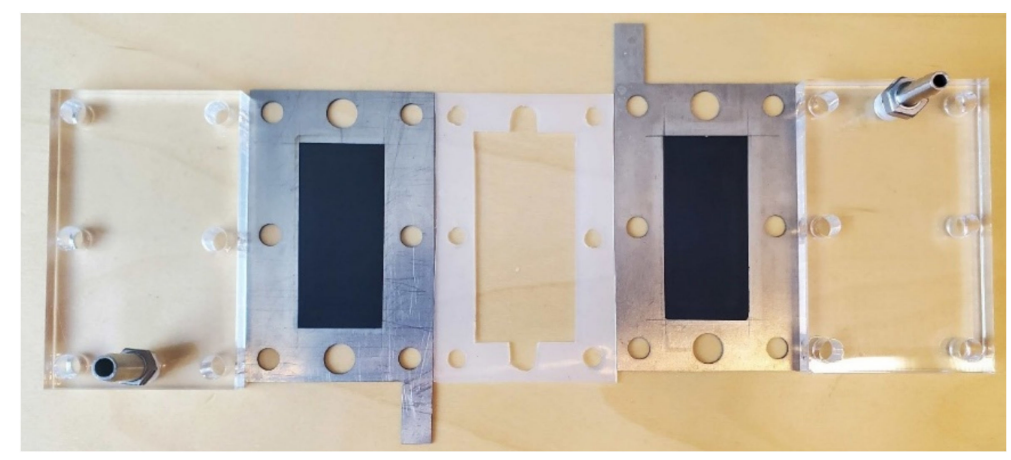

(a)

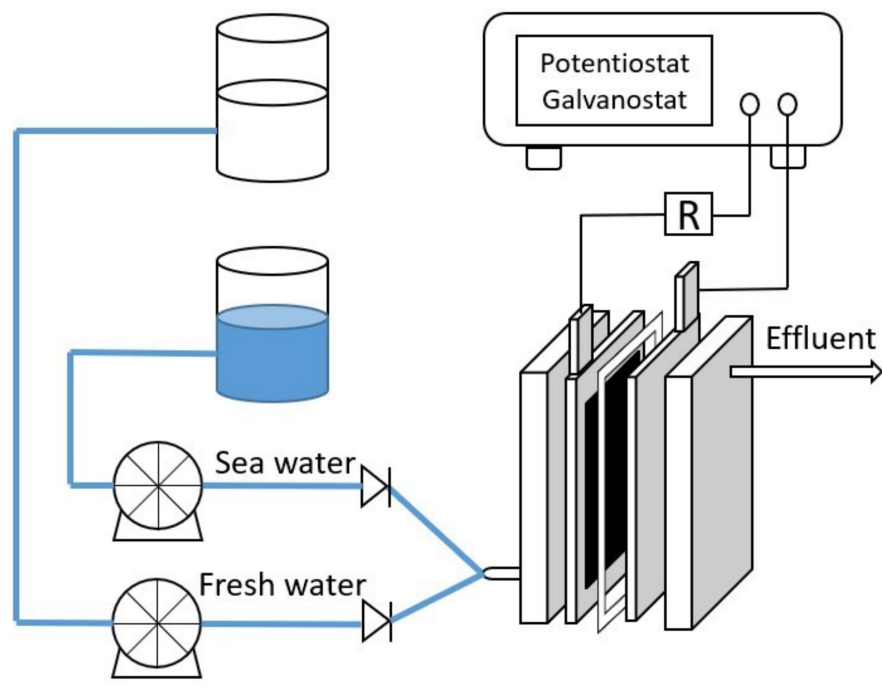

(b)

Figure 1. (a) Photograph of the CDLE cell, from left to right: acrylic plate, titanium current collector with electrode, silica gel tablet, titanium current collector with electrode, acrylic plate. (b) Schematic of the CDLE experiment setup.

Table 1. The specific surface area $\left(S_{B E T}\right)$, microporous surface area measurement $\left(S_{\text {micro }}\right)$, total volume of pores $\left(V_{t o t}\right)$, volume of micropores $\left(V_{\text {micro }}\right)$, characteristic pore thickness $\left(H_{p}\right)$ and average pore diameter $\left(D_{B J H}\right)$ results of activated carbon and electrode.

\begin{tabular}{ccccccc}
\hline Materials & $\begin{array}{c}S_{\text {SET }} \\
\left(\mathbf{m}^{2} / \mathbf{g}\right)\end{array}$ & $\begin{array}{c}S_{\text {micro }} \\
\left(\mathrm{m}^{2} / \mathbf{g}\right)\end{array}$ & $\begin{array}{c}V_{\text {tot }} \\
\left(\mathrm{cm}^{3} / \mathrm{g}\right)\end{array}$ & $\begin{array}{c}V_{\text {micro }} \\
\left(\mathrm{cm}^{3} / \mathbf{g}\right)\end{array}$ & $\begin{array}{c}H_{p} \\
(\mathbf{n m})\end{array}$ & $\begin{array}{c}D_{B J H} \\
(\mathbf{n m})\end{array}$ \\
\hline $\begin{array}{c}\text { Raw Activated } \\
\begin{array}{c}\text { Carbon } \\
\text { Fabricated } \\
\text { Electrode }\end{array}\end{array}$ & 1659.457 & 1176.362 & 0.835 & 0.502 & 0.427 & 3.805 \\
\hline
\end{tabular}

With the fabricated electrodes, the CDLE cell was also self-made. As illustrated in Figure 1 for the structure and component, it was composed of two rectangular acrylic plates, one pair of activated carbon electrodes, one pair of titanium current collectors and a hollow silica gel tablet with a thickness of $0.5 \mathrm{~mm}$ that form a flow channel between two electrodes. 


\subsection{Operations}

Our experiments consist of two parts: (i) a single-pass experiment with a constant voltage charge and (ii) a full-cycle experiment.

As schematically shown in Figure 1b, the experimental setup consists of two containers for fresh and seawater, respectively, two peristaltic pumps (BT100J-1A, HUIYU WEIYE Fluid Equipment Co., Ltd., Beijing, China), a CDLE cell and a potentiostat (PGSTAT30, Metrohm Autolab, Utrecht, The Netherlands) that is used to maintain a constant voltage between the electrodes and measure the change in current.

Before each experiment, the electrodes were short-circuited to ensure that no external charge was left on the electrodes, and the cell was fully flushed by deionized water until the effluent conductivity reached a stable value. The details of the two sets of experiments are summarized in what follows.

(i) Single-pass experiment: The experiments were performed in a single pass mode to investigate the amount of total charge stored on activated electrodes at equilibrium, using $\mathrm{NaCl}$ solution with a concentration of 5,20,100, 200 and $600 \mathrm{mM}$, respectively. It consists of two steps. In the charge step, a fixed electrical voltage ( 0.1 to $1.0 \mathrm{~V})$ was applied to the cell when the feed solution was continuously passing through the cells. The charged positive and negative ions in the solution were then adsorbed into the EDL that was formed near the electrode surface, and as a result of the movement of charged ions, an electric current was generated. This step continued until an equilibrium state was reached. The total electrode charge per mass $Q(\mathrm{C} / \mathrm{g})$ can, therefore, be calculated by integrating the electric current $I$ over the charging time $t(\mathrm{~s})$ and then divided by the mass of total electrodes in the cell $m_{\text {elec }}$, as [29]:

$$
Q=\frac{\int I d t}{m_{\text {elec }}}
$$

Following the charge step, a zero voltage is immediately applied over a sufficiently long time to remove any ions adsorbed in the electrodes.

To illustrate how the current varies with time in the charge and discharge steps, we show in Figure 2 the current profiles obtained at $V_{\text {ext }}=0.2,0.6$ and $1.0 \mathrm{~V}$ with a solution concentration of $600 \mathrm{mM}$. It is seen clearly that the current $I$ dropped quickly at the initial stage of charging. After around $100 \mathrm{~s}$, the electrodes were nearly saturated with charged ions as the electric current $I$ of the circuit has reached a stable value that closes to zero. At this moment, the cell could be deemed to reach an equilibrium state.

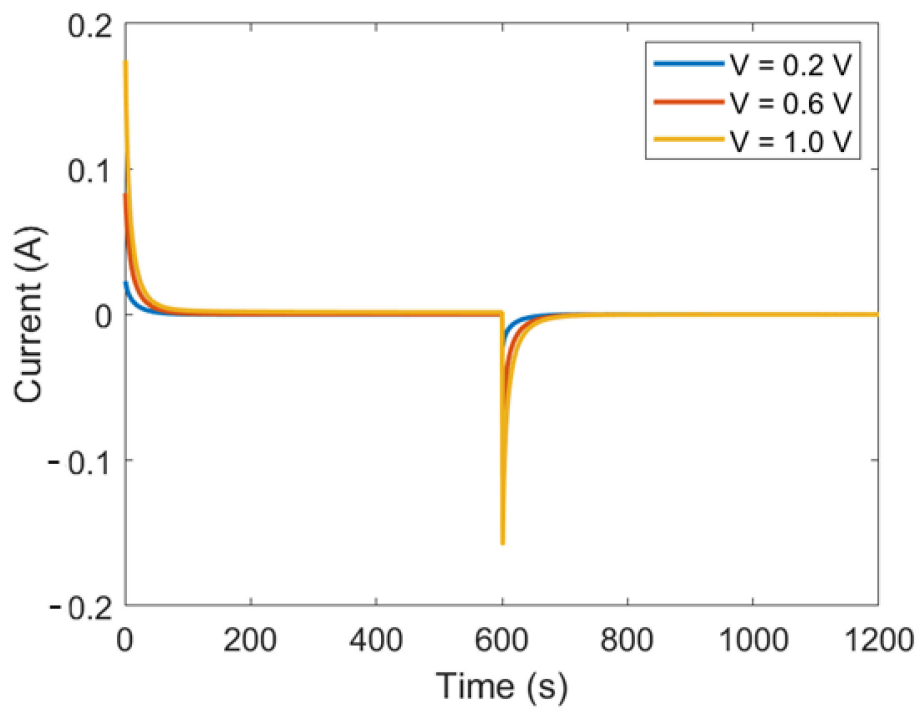

Figure 2. Electrical current as a function of time during the charging and discharging step. The applied voltage $V=0.2,0.6$ and $1.0 \mathrm{~V}$, solution concentration $c=600 \mathrm{mM}$. 
The small electric current at the end of the charging step is known as the leakage current $I_{\text {lea }}$, and it should be subtracted from the measured current $I_{m e a}$ to give the net current $I=I_{\text {mea }}-I_{\text {lea }}$, used in calculating the electrode charge $Q$ at equilibrium in Equation (1).

(ii) Full-cycle experiment: in this set of experiments, we used $20 \mathrm{mM}$ and $600 \mathrm{mM}$ $\mathrm{NaCl}$ solutions as the freshwater and seawater, respectively. These solutions were supplied intermittently to the CDLE cell by a peristaltic pump at a flow rate of $10 \mathrm{~mL} / \mathrm{min}$. To harvest the energy, we connect an external resistance $R_{\text {ext }}=100 \Omega$ to the cell. As a result, the voltage across the cell can be calculated by: $V=V_{\text {ext }}-I \cdot R_{\text {ext }}$.

A complete cycle CDLE process consists of four steps (Figure 3). In step 1, the circuit was closed, and the cell, immersed with seawater, was charged by a fixed voltage $V_{\text {ext }}(0.2$ to $0.9 \mathrm{~V}$ ) until the cell potential $V$ becomes equal to $V_{\text {ext }}$. This is followed by step 2, the circuit was opened, and the freshwater was pumped into the cell to replace the seawater until the cell potential increased to a stable value $\left(V_{\text {fresh }}\right)$. Then in Step 3, the circuit was closed, and the cell was discharged at the same external voltage $V_{\text {ext }}$ as it in Step 1, this step continued until the cell potential $V$ decreases to the $V_{\text {ext }}$. Finally in Step 4, the freshwater in the cell was replaced by the seawater until the cell potential $V$ declined to a stable value $\left(V_{\text {salt }}\right)$. The surface area enclosed in the cycle in Figure 3 represents, therefore, the extracted energy, i.e.,

$$
W=\oint V(Q) \mathrm{d} Q
$$

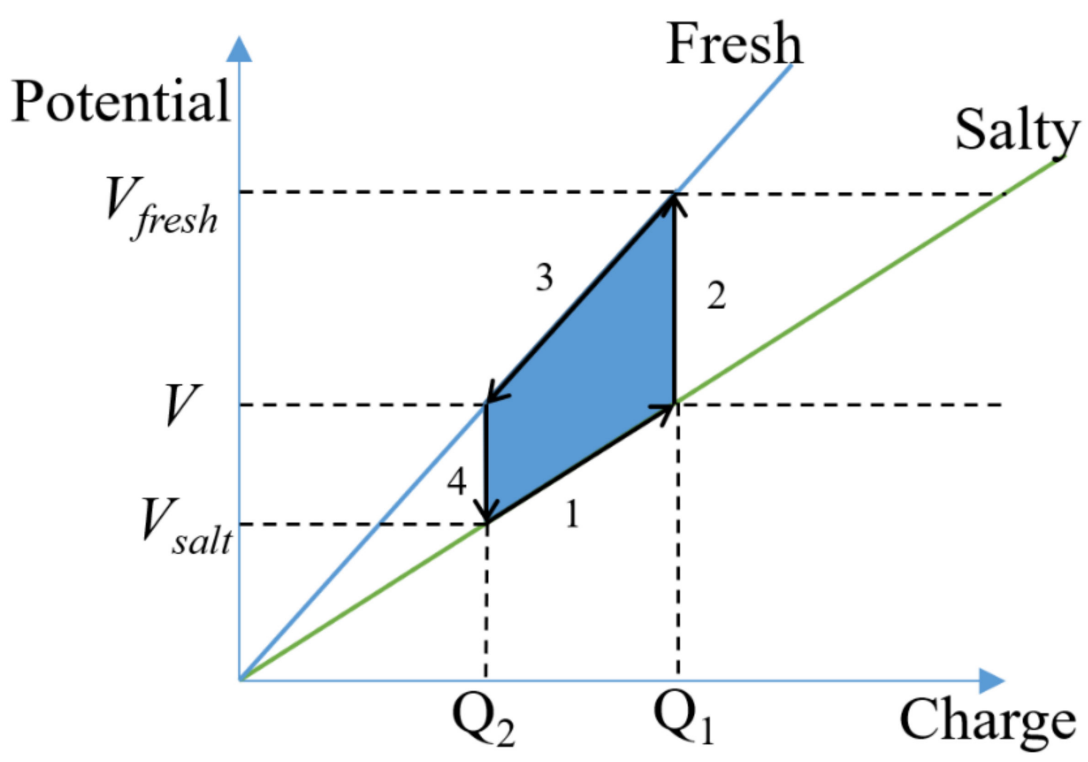

Figure 3. Schematic of the relation between the cell potential and the electrode charge at one CDLE cycle.

The corresponding $V-t$ profile is exemplified in Figure 4a for the case of $V_{e x t}=0.2 \mathrm{~V}$, which shows that the equilibrium cell potential can only reach $0.185 \mathrm{~V}$ due to the use of a large external resistance load in the circuit. The result with respect to the $Q-V$ cycle is shown in Figure $4 b$, which mimics closely the theoretical plot in Figure 3 and therefore suggests the success of our experiments. 


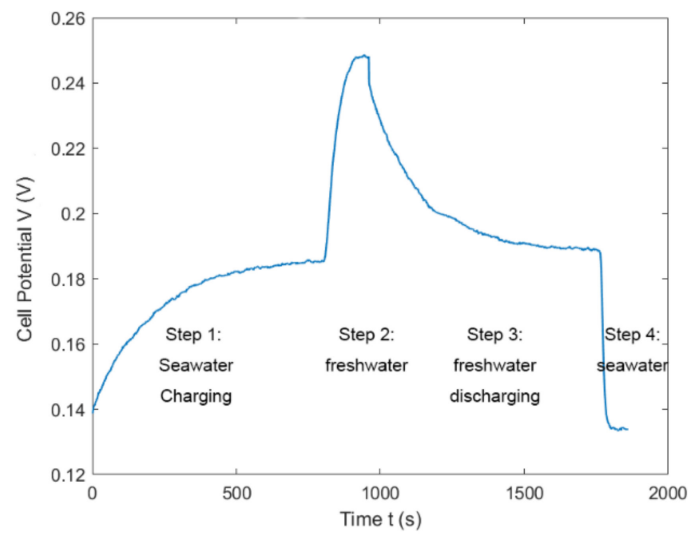

(a)

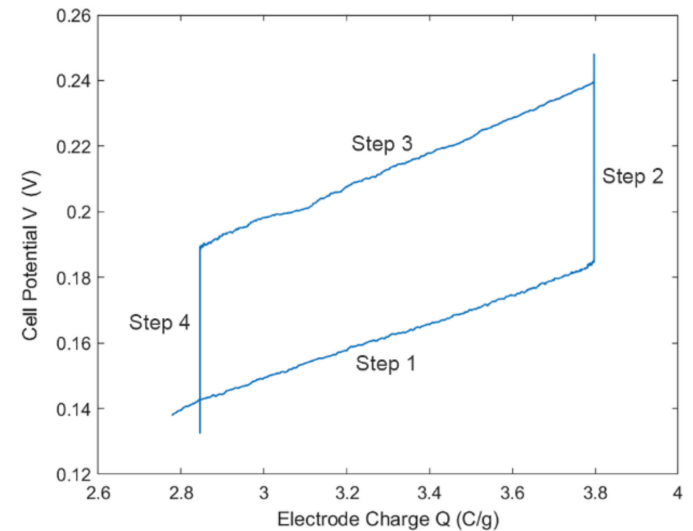

(b)

Figure 4. A full CDLE cycle at the applied voltage $V_{\text {ext }}=0.2 \mathrm{~V}, R_{\text {ext }}=100 \Omega, c_{\text {fresh }}=20 \mathrm{mM}, c_{\text {sea }}=600 \mathrm{mM}$. (a) Cell potential $V$ as a function of time $t ;(\mathbf{b})$ cell potential $V$ as a function of electrode charge $Q$.

\section{Theory of Electrical Double Layers}

The mechanism behind CDLE is the formation of EDL near the electrode surface and the change in the properties of EDL when the concentration of the solution is changed. Therefore, a proper description of the structural and thermodynamic properties of EDLs at equilibrium is of great importance for understanding the performance of the CDLE technique. For this reason, we may start with a summary of the basic assumptions and simplifications about activated carbon electrodes when applying different EDL models. These include [30-33]:

(i) the electrodes are symmetric, meaning that the applied voltage is equally distributed over each electrode and the adsorption amount of the anion in the anode is equal to that of cation in cathode;

(ii) The electric potential of the anode is opposite to that of the cathode in sign but is equal in magnitude;

(iii) the adsorbed ions are positioned only on the surface of electrode particles, meaning that they cannot become part of the electrode matrix.

With these common considerations, different EDL models have been developed over the years to remedy the inherent defects of the Poisson-Boltzmann theory, as shown schematically in Figure 5 and detailed in what follows for the GCS, MPBS and mD models, respectively.
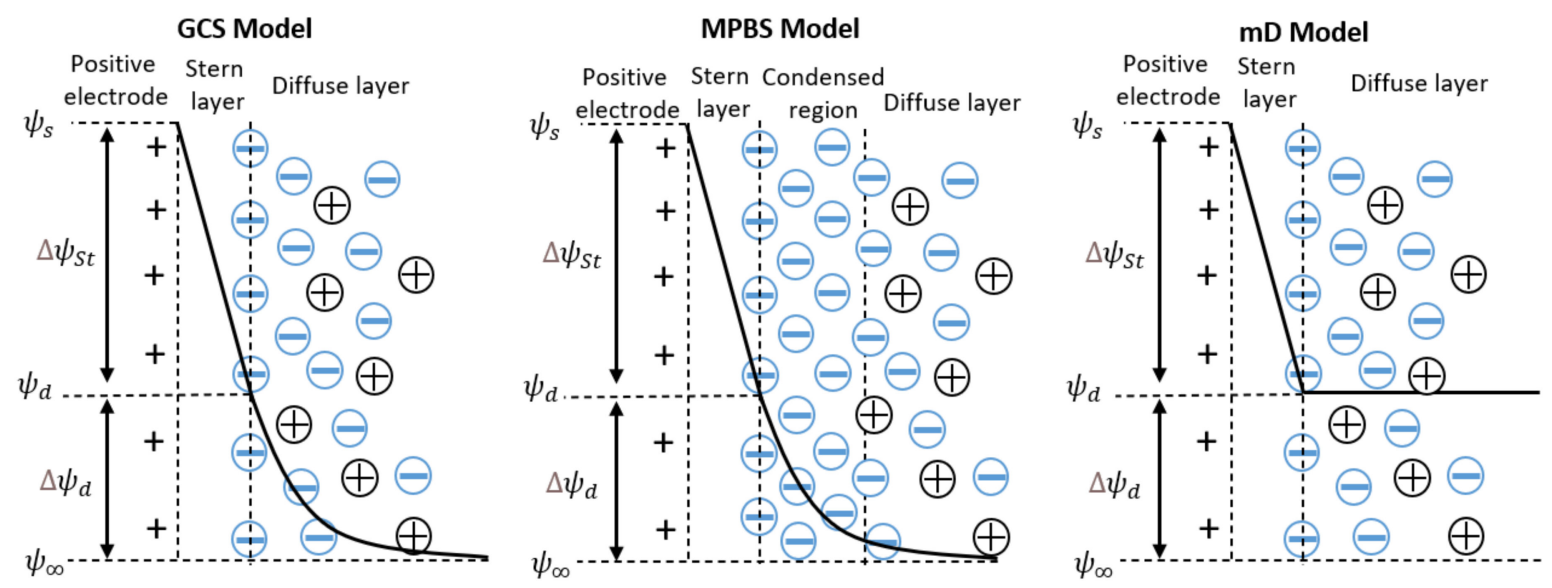

Figure 5. Schematic view of GCS, MPBS and $\mathrm{mD}$ models. 


\subsection{Gouy-Chapmann-Stern Model}

The GCS model is the simplest extension of the PB theory in accounting for the effect of the finite size of ions. As illustrated Figure 5, it conceptualizes the structure of EDLs near the electrode surface as being composed of two layers: (i) a compact Stern layer where the ions are immobile and strongly adsorbed to the electrode surface, with a thickness corresponding to the closest approach of hydrated ions to the electrode surface; (ii) a diffuse layer where thermal motion causes the ions to be spread out in space.

It follows that no free charges exist in the Stern layer, while the distribution of ions in the diffuse layer can still be described by the Boltzmann equation, i.e.,

$$
n_{i}=n_{i, \infty} \exp \left(-\frac{z_{i} e \psi}{k_{B} T}\right)
$$

where $\psi$ is the electric potential $(\mathrm{V}), n_{i, \infty}$ is number density $\left(1 / \mathrm{m}^{3}\right)$ of the $i$ th species at the bulk solution, e is the elementary charge $(\mathrm{C}), z_{i}$ is the valence of the $i$ th species and $k_{B}$ is the Boltzmann constant $(\mathrm{J} / \mathrm{K})$, respectively.

The distribution of electric potential can, therefore, be described by the Poisson equation as

$$
\nabla \times\left(\varepsilon_{0} \varepsilon_{r} \nabla \psi\right)=-e \sum_{i} z_{i} n_{i}
$$

where $\varepsilon_{0}$ and $\varepsilon_{r}$ are the free space permittivity and the relative permittivity of the electrolyte solutions, $\nabla$ is the divergence operator.

As a result, the GCS model can be expressed as:

$$
\nabla^{2} \psi=\left\{\begin{array}{cc}
0 & \text { in Stern layer } \\
-\frac{e}{\varepsilon_{0} \varepsilon_{r}} \sum z_{i} n_{i, \infty} \exp \left(-\frac{z_{i} e \psi}{k_{B} T}\right) & \text { in Difuse layer }
\end{array}\right.
$$

subject to the following boundary conditions:

$$
\begin{gathered}
\left.\psi\right|_{x=0}=\psi_{s} \\
\left.\psi\right|_{x=\delta^{-}}=\left.\psi\right|_{x=\delta^{+}} \\
\left.\frac{d \psi}{d x}\right|_{x=\delta^{-}}=\left.\frac{d \psi}{d x}\right|_{x=\delta^{+}} \\
\left.\psi\right|_{x \rightarrow \infty}=0
\end{gathered}
$$

where $x$ is the normal distance from the electrode surface, $\delta$ is the thickness of the Stern layer and $\psi_{s}$ is the surface potential, $\nabla^{2}$ is the Laplace operator.

The GCS model, as given above, is quite general in that it can be applied to electrode particles with any geometry immersed in any electrolyte solution and can readily be solved numerically to obtain the relation between the surface potential $\psi_{s}$ and the surface charge $\sigma_{s}$. When used in practice, however, it is commonly assumed that the particle is of planar geometry and that the electrolyte is symmetric. For this special case, the analytical solution to the GCS model can be obtained to give the profile of electric potential $\psi$ as a function of $x$,

$$
\psi=\left\{\begin{array}{cc}
\psi_{s}-\Delta \psi_{S t} \times x / \delta & \text { in Stern layer } \\
\frac{4 k_{B} T}{e} \tanh ^{-1}\left(\frac{e \Delta \psi_{d}}{k_{B} T}\right) \exp \left(\frac{x-\delta}{\lambda_{D}}\right) & \text { in Diffuse layer }
\end{array}\right.
$$

with the Debye length $\lambda_{D}$ given by:

$$
\lambda_{D}=\sqrt{\frac{\varepsilon_{0} \varepsilon_{r} k_{B} T}{2 e^{2} n_{i, \infty}}}
$$


where $\Delta \psi_{S t}$ is the electric potential drop across the Stern layer, $\Delta \psi_{S t}=\psi_{s}-\psi_{d}, \Delta \psi_{d}$ is the electric potential difference across the diffuse layer, $\Delta \psi_{d}=\psi_{d}-\psi_{\infty}$ and $\psi_{d}$ and $\psi_{\infty}$ are the electric potential at the outer Stern plane and in the bulk solution, respectively.

It follows from Gauss' law that the surface charge $\sigma_{s}$ can be related to both $\Delta \psi_{S t}$ and $\Delta \psi_{d}$ as

$$
\sigma_{s}=-\left.\varepsilon_{0} \varepsilon_{r}\left(\frac{\mathrm{d} \psi}{\mathrm{d} x}\right)\right|_{x=0}=-\varepsilon_{0} \varepsilon_{r} \frac{\Delta \psi_{S t}}{\delta}=\sqrt{8 n_{\infty} \varepsilon_{0} \varepsilon_{r} k_{B} T} \sinh \left(\frac{z e \Delta \psi_{d}}{2 k_{B} T}\right)
$$

The total differential capacitance of the double layer, $C$, can then be given by

$$
\frac{1}{C}=\frac{1}{C_{S t}}+\frac{1}{C_{d}}
$$

where $C_{s t}$ and $C_{d}$ are the differential capacitances to the Stern layer and the diffuse layer, respectively, with

$$
C_{S t}=-\frac{d \sigma_{S}}{d \Delta \psi_{S t}}=\frac{\varepsilon_{0} \varepsilon_{r}}{\delta}
$$

and

$$
C_{d}=-\frac{d \sigma_{s}}{d \Delta \psi_{d}}=\frac{\varepsilon_{0} \varepsilon_{r}}{\lambda_{D}} \cosh \left(\frac{z e \Delta \psi_{d}}{2 k_{B} T}\right)
$$

As a result, the surface charge density $\sigma_{S}$ from Equation (12) can also be written as a product of $\Delta \psi_{S t}$ and $C_{S t}$, i.e.,

$$
\sigma_{S}=-\Delta \psi_{S t} \times C_{S t}
$$

\subsection{Modified Poisson-Boltzmann-Stern Model}

The GCS model accounts for the effect of the finite size of ions only in the Stern layer but treats the ions in the diffuse layer still as point-charges. In the case of high ion concentration and high surface potential, however, the interfacial region can be largely enriched in counterions to the extent that the point charge hypothesis for the EDL structure leads to unrealistically high counterion concentrations in the vicinity of the solid/solution interface [34]. This fact means a non-negligible role of the size of the ions, even in the diffuse layer, and therefore, as illustrated in Figure 5, a maximum ion concentration must exist corresponding to the closed packing of ions. As a result, the model for the diffuse layer should properly be modified to address the non-ideal behavior of ions therein. This leads Bikerman [34-36] to arrive at, by means of the approximate "free volume" approach:

$$
n_{i}=\frac{n_{i, \infty} \exp \left(-\frac{z_{i} e \psi}{k_{B} T}\right)}{1+v \sum_{k} n_{k, \infty}\left[\exp \left(-\frac{z_{k} e \psi}{k_{B} T}\right)-1\right]}
$$

where $v$ has the meaning of average excluded volume per ion.

When combined with the Poisson equation and consideration of a Stern layer, the MPBS model can be written for a $(z: z)$ symmetric electrolyte as,

$$
\nabla^{2} \psi=\left\{\begin{array}{c}
0 \quad \text { in Stern layer } \\
-\frac{e}{\varepsilon_{0} \varepsilon_{r}} \frac{2 z n_{\infty} \sinh \left(\frac{z e \psi}{k_{B} T}\right)}{1+2 v \sinh ^{2}\left(\frac{z e \psi}{2 k_{B} T}\right)} \quad \text { in Diffuse layer }
\end{array}\right.
$$

with

$$
v=2 d^{3} n_{\infty}
$$

where $d$ is the spacing of counterions near a highly charged surface, and it is unnecessarily the diameter of the counterions. One may think of it as a cutoff [36] for the unphysical divergences of PB theory and could include at least a solvation shell (ion-ion correlations could effectively increase it further). 
Equation (18) should also be subject to the same boundary conditions of Equations (6)-(9) as the GCS model, and therefore it is also convenient to be solved numerically. However, for a planer electrode surface, an analytical solution to the surface charge density $\sigma_{s}$ is available for a symmetric electrolyte and it can be written as,

$$
\sigma_{s}=-2 z e n_{\infty} \lambda_{D} \sqrt{\frac{2}{v} \ln \left[1+2 v \sinh ^{2}\left(\frac{z e \Delta \psi_{d}}{2 k_{B} T}\right)\right]}
$$

The relation between $\sigma_{s}$ and $\Delta \psi_{S t}$, as given in Equation (16), also holds in the MPBS model.

\subsection{Modified Donnan Model}

When dealing with the experimental results of CDLE processes, the application [28] of both GCS and MPBS models implicitly assume that the characteristic pore thickness is much larger than the Debye screening length so that the pore space is mostly filled with quasi-neutral electrolyte, exchanging ions with a charged, thin double-layer "skin" on the electrode matrix. This is, however, far from realistic because the activated carbon particles are themselves porous, presenting a very large specific surface inside the small micropores $(\leq 2 \mathrm{~nm})$. Therefore, as schematically shown in Figure 6, the free space between different carbon particles filled with electroneutral solution constitutes a macro-porosity that serves as a path for salt and charge transport, whereas the micropores store ionic charge in their EDLs. This fact implies that both GCS and MPBS descriptions of the EDL are not valid inside the micropores of activated carbon particles, which have a size comparable to the EDL thickness and even to that of hydrated ions, leading to EDLs overlap and other complications, such as the observed exceptionally large values of the capacitance.

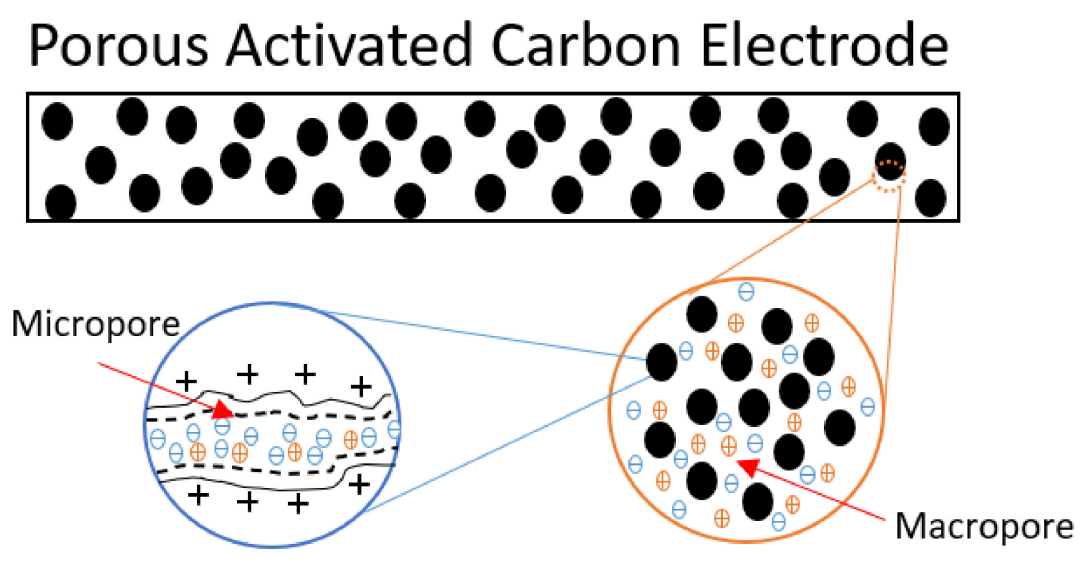

Figure 6. Schematic view of the structure of porous electrode.

To tackle this problem, Biesheuvel et al. [37] combined a modified Donnan description of the diffuse layer together with a charge-free Stern layer to determine the voltage drop at the carbon/solution interface inside the micropores. The main assumption of the $\mathrm{mD}$ approach is that the diffuse layer potential inside the micropores is constant, as illustrated in Figure 5, and it is controlled by the concentration of ions in the macropores of the electrode matrix, i.e., one can write [37]

$$
n_{i, m i}=n_{i, \infty} \exp \left(-\frac{z_{i} e \Delta \psi_{d}}{k_{B} T}+\mu_{a t t}\right)
$$

where the subscript "mi" emphasizes that it applies only to micropores, $\Delta \psi_{d}$ is now known as the Donnan potential and $\mu_{a t t}$ is an excess chemical potential that quantifies the chemical attraction between ions and carbon material of the electrodes [37]. 
This allows one to introduce the concept of volumetric charge density as the number of charges removed from solution per unit micropore volume, and in the case of a symmetric binary $z: z$ electrolyte, it is given by [31]

$$
\rho=-2 z e n_{\infty} \exp \left(\mu_{a t t}\right) \times \sinh \left(\frac{z e \Delta \psi_{\mathrm{d}}}{k_{B} T}\right)
$$

and

$$
\rho=-C_{S t, v o l} \Delta \psi_{S t}
$$

where $C_{S t, v o l}$ is the volumetric capacitance $\left(\mathrm{F} / \mathrm{m}^{3}\right)$ of the Stern layer, and it was suggested to be quantified empirically by $[38,39]$

$$
C_{S t, v o l}=C_{S t, v o l, 0}+\alpha \times\left(\frac{\rho}{F}\right)^{2}
$$

with both $C_{S t, v o l, 0}$ and $\alpha\left(\mathrm{F} \cdot \mathrm{m}^{3} / \mathrm{mol}^{2}\right)$ being determined by fitting the $\mathrm{mD}$ model to the experimental data.

One key of the $\mathrm{mD}$ model is to describe the excess chemical potential properly, $\mu_{a t t}$. For simplicity, it was generally taken as a constant irrespective of the specific type of ions [30,38]. Although this assumption makes the $\mathrm{mD}$ model works well for some cases, it cannot describe the experimental data in a range of bulk salt concentrations simultaneously [37]. An improved modified Donnan model (i-mD model) was developed [39] to rectify this problem by relating $\mu_{\text {att }}$ with the micropore total ion concentration $c_{\text {ions,mi }}$, based on the theory of image forces, to give

$$
\mu_{\text {att }}=\frac{E}{c_{\text {ions }, m i}}
$$

with the energy parameter $\left(\mathrm{kT} \mathrm{mol} / \mathrm{m}^{3}\right), E$, defined as

$$
E=z^{2} \times k_{B} T \times \lambda_{B} \times d_{p}^{-4}
$$

where $\lambda_{B}$ is the Bjerrum length, $\lambda_{B}=e^{2} / 4 \pi \varepsilon_{0} \varepsilon_{r} k_{B} T$, at which the bare Coulomb energy of a pair of ions is balanced by thermal energy $\left(\lambda_{B}=0.72 \mathrm{~nm}\right.$ in water at room temperature), and $d_{p}$ is the size of micropore.

\subsection{Booth Correction of Dielectric Permittivity}

In most applications of the GCS and MPBS models, the solvent dielectric permittivity was assumed to be a constant or was treated as a fitting parameter. However, it is known that with the increase in the electric field, the relative permittivity of solvent $\varepsilon_{r}$ shows a decreasing trend. The reason for this is that under a large electric field condition, electrolyte molecules become highly oriented, which results in poor capability of providing polarization [40]. To account for this effect of dielectric saturation into EDL models, Booth [41,42] derived the following equations to calculate the relative electrolyte permittivity under the local electric field condition as:

$$
\varepsilon_{r}(E)=\left\{\begin{array}{cc}
m^{2}+\left(\varepsilon_{r}(0)-m^{2}\right) \frac{3}{\beta E}\left[\operatorname{coth}(\beta E)-\frac{1}{\beta E}\right] & \text { for } E \geq 10^{7} \mathrm{~V} / \mathrm{m} \\
\varepsilon_{r}(0) & \text { for } E<10^{7} \mathrm{~V} / \mathrm{m}
\end{array}\right.
$$

with

$$
\beta=\frac{5 \mu}{2 k_{B} T}\left(m^{2}+2\right)
$$

where $E=|-\nabla \psi|$ is the norm of the local electrical field vector, $\varepsilon_{r}(0)$ is the relative permittivity at zero electric field, $m$ is the index of refraction of the electrolyte at zero electric field frequency, $\mu$ is the dipole moment of the solvent molecule, and in the case of water, $\mu=1.85 \mathrm{D}$ (Debye). 
For aqueous binary symmetric electrolytes at room temperature ( $T=298 \mathrm{~K})$, one may set [40,43]: $\varepsilon_{r}(0)=78.5, m=1.33$ and $\beta=1.41 \times 10^{-8} \mathrm{~m} / \mathrm{V}$. The result for the relative permittivity as a function of the electric field is shown in Figure 7. It suggests that $\varepsilon_{r}$ may change significantly from 78.5 in the bulk solution to 1.79 near the electrode surface in the cases where the electric field is very strong.

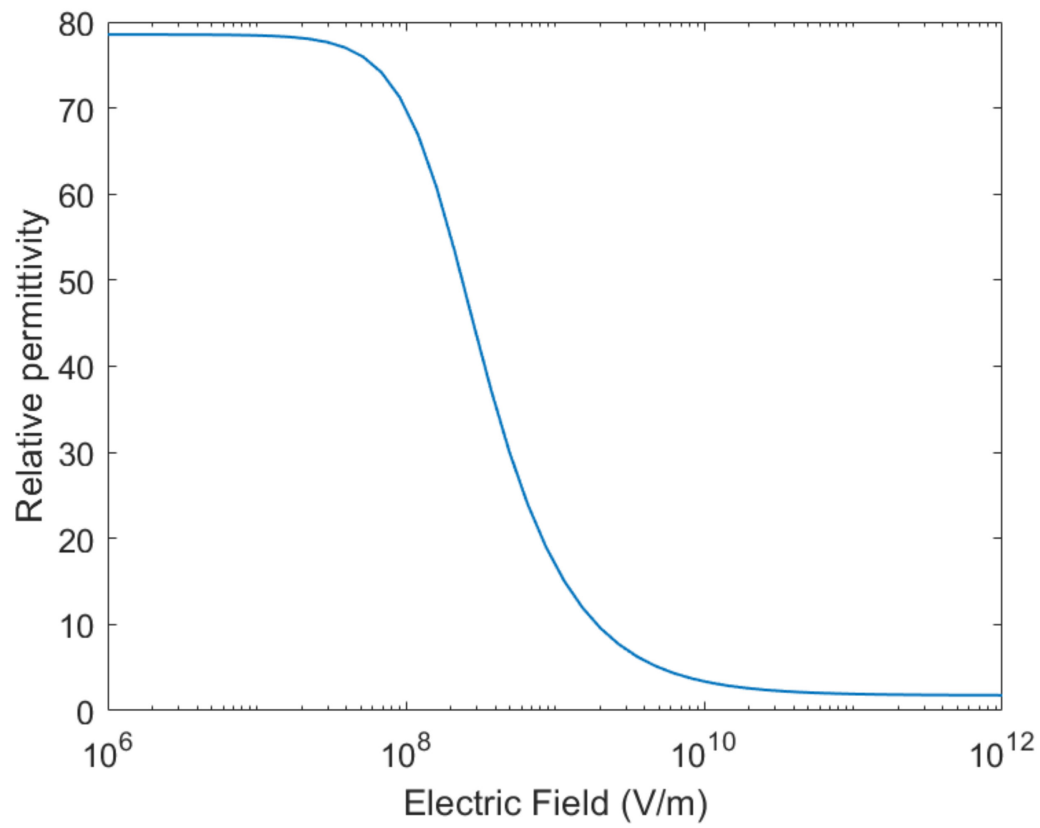

Figure 7. The relative permittivity $\varepsilon_{r}(E)$ as a function of electric field.

The importance of the Booth correction of dielectric permittivity is, therefore, that it may be used to account for the non-ideal behavior (or excess chemical potential) of ions in EDLs in a different way than MPBS and mD models and that it can be combined with either GCS or MPBS model for the performance assessment of CapMix processes.

\section{Experimental Results and Model Applications}

The key property of the CDLE cells is the dependence of the equilibrium electrode charge $Q$ on the applied voltage $V$ under different electrolyte concentrations, also known as the $Q-V$ curves. The applicability of different EDL models can, therefore, be justified by comparing the simulated $Q-V$ curves with the results of single-pass experiments.

\subsection{Gouy-Chapmann-Stern Model}

As discussed above, the GCS model is usually applied to the cases where the Debye screening length of the EDL, $\lambda_{D}$, is much less than the characteristic pore thickness $H_{p}$ so that a planer electrode surface could effectively be defined. As a result, $Q(\mathrm{C} / \mathrm{g})$ can simply be evaluated by multiplying $\sigma_{s}$ with the specific electrode area $S_{\text {eff }}\left(\mathrm{m}^{2} / \mathrm{g}\right)$ as:

$$
Q=\frac{1}{2} \sigma_{s} \times S_{\text {eff }}
$$

The corresponding voltage drop across the cell can, by assuming it to be evenly distributed on the two electrodes, relate to $\Delta \psi_{S t}$ and $\Delta \psi_{d}$ directly as:

$$
V=2\left(\Delta \psi_{S t}+\Delta \psi_{d}\right)
$$

With these definitions, the GCS model can readily be applied to the CDLE cell to obtain the $Q-V$ curves under different electrolyte concentrations. Since it is commonly assumed in the GCS model that $\varepsilon_{r}=\varepsilon_{r}(0)$, the unknown parameters of the specific system 
only involve $C_{s t}$ and $S_{\text {eff }}$. As a result, we may fix $\varepsilon_{r}=78.5$ at $T=298 \mathrm{~K}$ and evaluate $C_{s t}$ and $S_{e f f}$ simultaneously by fitting the simulated $Q-V$ curves to the measured data over all the $\mathrm{NaCl}$ concentrations of interest by using a nonlinear least square algorithm, supplemented with suitable lower and upper bounds. The result gives $C_{S t}=0.131 \mathrm{~F} / \mathrm{m}^{2}$ and $S_{e f f}=619.46 \mathrm{~m}^{2} / \mathrm{g}$. At first glance, a good agreement between the calculated and measured $Q-V$ curves, as shown in Figure 8 and the fact that $S_{e f f}=619.46 \mathrm{~m}^{2} / \mathrm{g}$ is comparable with the findings of reported results $[19,22,23]$ seems to substantiate the rationale of $C_{s t}$ and $S_{\text {eff }}$ values. However, further analysis suggests that $C_{S t}=0.131 \mathrm{~F} / \mathrm{m}^{2}$ corresponds to a Stern layer thickness of $5.3 \mathrm{~nm}$. This is far greater than the hydrated radius [44] of $\mathrm{Na}+$ ions and is therefore unreasonable, meaning that an arbitrary setting of $C_{S t}=0.1 \mathrm{~F} / \mathrm{m}^{2}$, as shown by previous work [21,22], is also problematic.

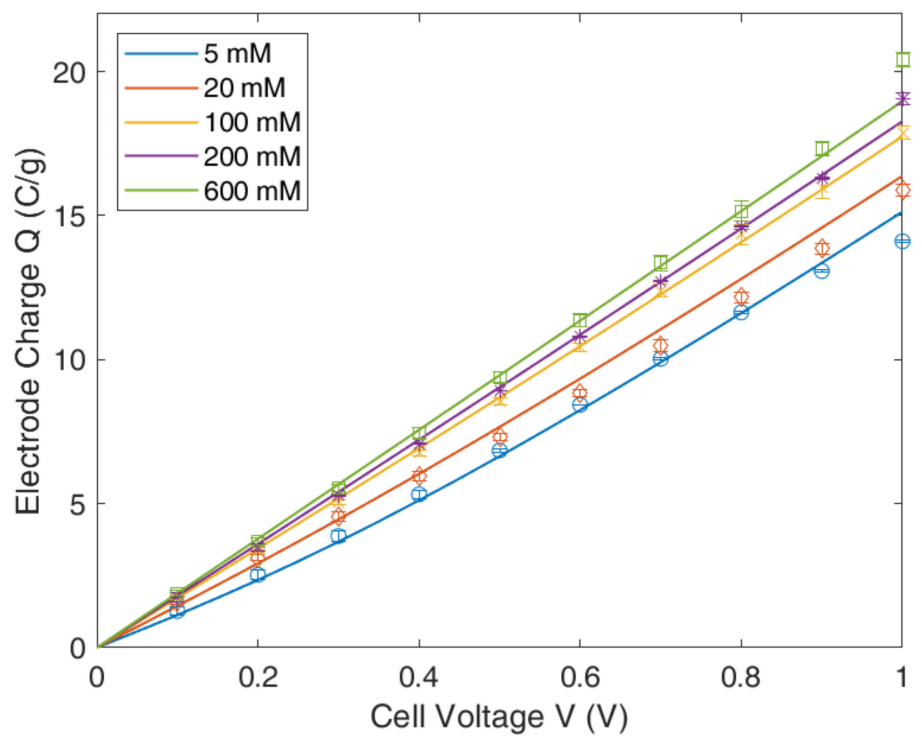

Figure 8. Equilibrium electrode charge $\mathrm{Q}$ versus applied voltage $\mathrm{V}$ for different values of $\mathrm{NaCl}$ solution. Lines refer to the results of GCS model $\left(C_{S t}=0.131 \mathrm{~F} / \mathrm{m}^{2}, S_{\text {eff }}=619.46 \mathrm{~m}^{2} / \mathrm{g}, \varepsilon_{r}=78.5\right)$, marks refer to the experiment data and error bars of the experimental data are indicated by horizontal lines through the marked data points.

On the other hand, it is noted from Table 1. that the characteristic pore thickness $H_{p}$ is on the order of magnitude of $0.43 \mathrm{~nm}$, whereas the Debye screening length of the EDL is about $0.4 \mathrm{~nm}$ at a bulk concentration of $600 \mathrm{mM}$. This suggests that $H_{p}$ is always smaller than $\lambda_{D}$ in all the cases studied, and therefore violates the assumption of thin double-layer "skin" on the electrode matrix. As a result, the GCS model is deemed to be not applicable, especially when the $\mathrm{NaCl}$ concentration is small.

If combined with Booth correction of dielectric permittivity, the GCS model gives even worse agreement, as shown in Figure 9, with $\delta=4.2 \mathrm{~nm}$ and $S_{e f f}=540.25 \mathrm{~m}^{2} / \mathrm{g}$. This suggests that accounting for the variation of $\varepsilon_{r}$ with the electric field does not remedy the inherent problem of the GCS model, still making the parameters physically meaningless, and therefore should also be abandoned in the interpretation of the experimental results.

\subsection{Modified Poisson-Boltzmann-Stern Model}

The MPBS model bears the same conceptualization on the EDL geometry as the GCS model but accounts for the effect of finite-size of ions. We can, therefore, still use Equations (29) and (30) to calculate $Q$ and $V$ in the simulations. As shown in Figure 10, the agreement between the calculated and measured $Q-V$ curves is nearly the same as the GCS model does, with $C_{S t}=0.141 \mathrm{~F} / \mathrm{m}^{2}$ and $S_{e f f}=580.88 \mathrm{~m}^{2} / \mathrm{g}$ when $\varepsilon_{r}$ is fixed at 78.5 . The minor difference between the $C_{S t}$ value of the two models also suggests that the MPBS model breaks down in the regime of experimental interest. 


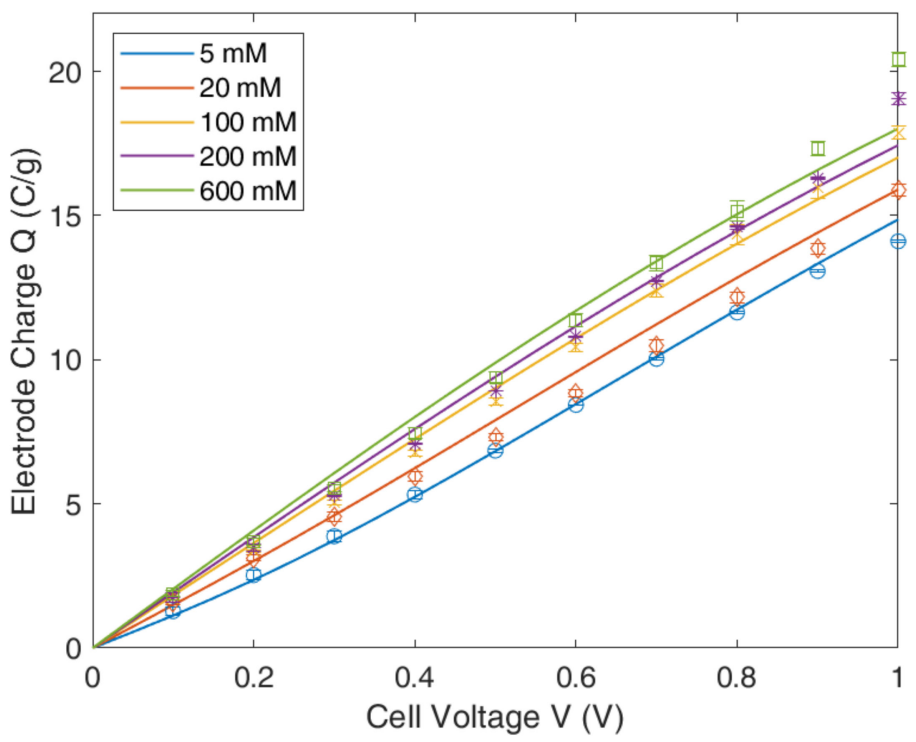

Figure 9. Equilibrium electrode charge $\mathrm{Q}$ versus applied voltage $\mathrm{V}$ for different values of $\mathrm{NaCl}$ solution. Lines refer to the results of the GCS model with Booth correction $\left(\delta=4.2 \mathrm{~nm}, S_{\text {eff }}=540.25 \mathrm{~m}^{2} / \mathrm{g}\right)$, marks refer to the experiment data and error bars of the experimental data are indicated by horizontal lines through the marked data points.

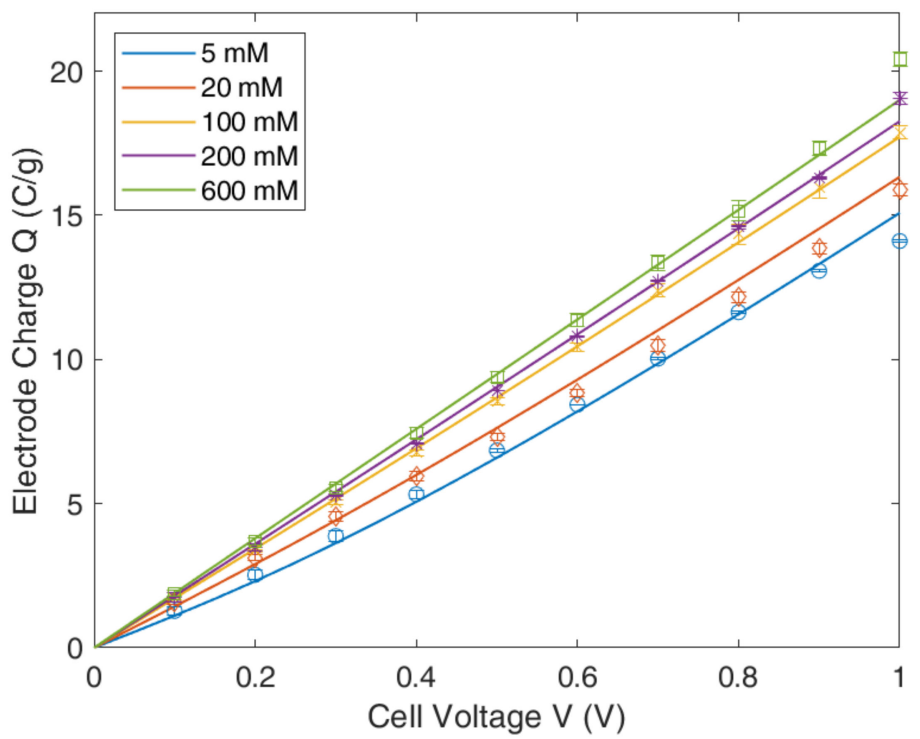

Figure 10. Equilibrium electrode charge $Q$ versus applied voltage $V$ for different values of $\mathrm{NaCl}$ solution. Lines refer to the results of MPBS model $\left(C_{S t}=0.141 \mathrm{~F} / \mathrm{m}^{2}, S_{e f f}=580.88 \mathrm{~m}^{2} / \mathrm{g}, \varepsilon_{r}=78.5\right.$, $d=0.75 \mathrm{~nm}$ ), marks refer to the experiment data and error bars of the experimental data are indicated by horizontal lines through the marked data points.

Not surprisingly, when combined with Booth correction, the MPBS model does not move the needle at all. It gives $\delta=7.3 \mathrm{~nm}, S_{\text {eff }}=857.79 \mathrm{~m}^{2} / \mathrm{g}$ and the spacing of counterions $d=1.42 \mathrm{~nm}$, with an acceptable agreement between the calculated and measured $Q-V$ curves, as shown in Figure 11. As a result, accounting for the variation of $\varepsilon_{r}$ with the electric field in the MPBS model does not help to rectify the problems associated with the model in the cases where the assumption of thin double-layer "skin" on the electrode matrix is not valid. 


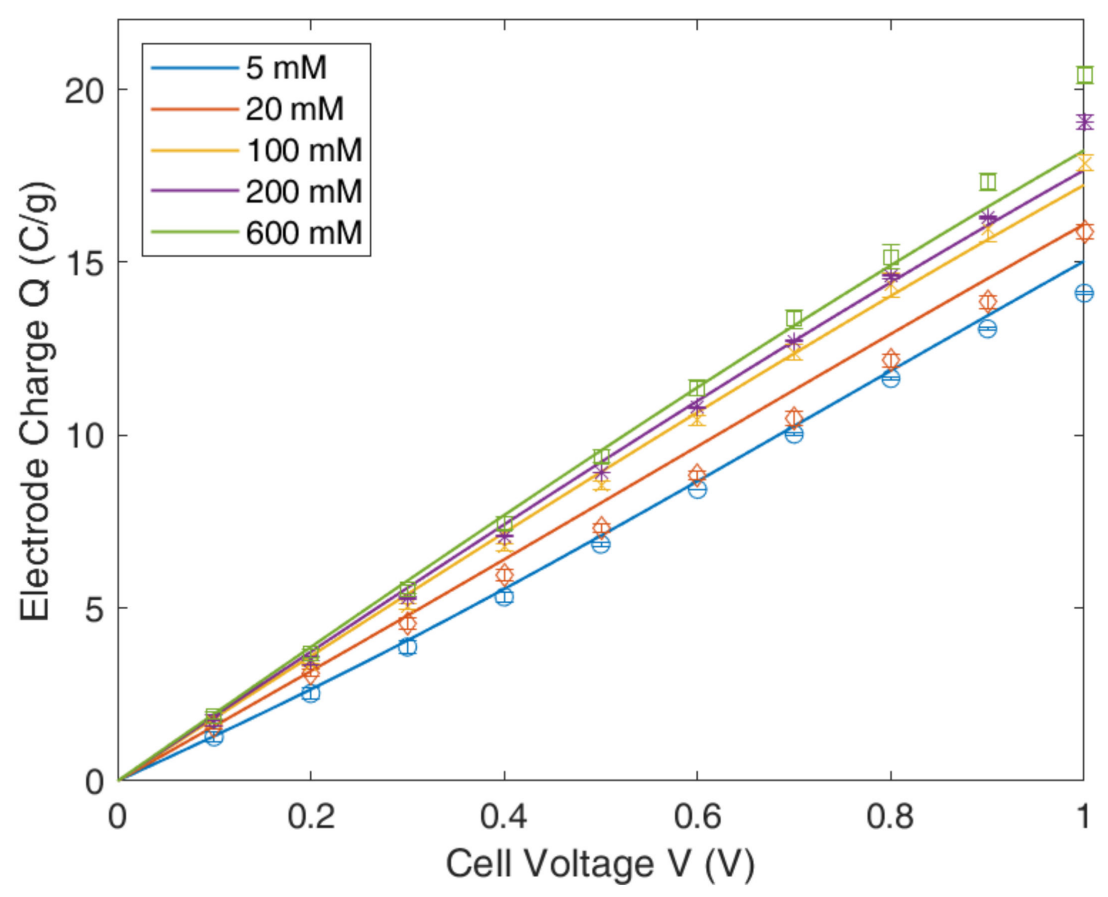

Figure 11. Equilibrium electrode charge $Q$ versus applied voltage $V$ for different values of $\mathrm{NaCl}$ solution. Lines refer to the results of MPBS model with Booth correction $\left(\delta=7.3 \mathrm{~nm}, S_{\text {eff }}=857.79 \mathrm{~m}^{2} / \mathrm{g}\right.$, $d=1.42 \mathrm{~nm}$ ), marks refer to the experiment data and error bars of the experimental data are indicated by horizontal lines through the marked data points.

\subsection{Modified Donnan Model}

In contrast to the GCS and MPBS models, the mD model considers that the micropores of activated carbon particles have a size comparable to the EDL thickness and even to that of hydrated ions, leading to EDLs overlap and a constant diffuse layer potential. The total charge in electrode at equilibrium can, therefore, be calculated as:

$$
Q=-\frac{1}{2} \times \rho \times v_{m i}
$$

where $v_{m i}$ is the micropore volume per unit electrode mass $\left(\mathrm{cm}^{3} / \mathrm{g}\right)$.

Using this expression for $Q$ and Equation (30) for $V$, the $Q-V$ curves of the CDLE cell under different electrolyte concentrations can conveniently be obtained in the mD model. The unknown parameters involved are, however, version-dependent. In the standard $\mathrm{mD}$ model $[29,30,38,39,45]$, where $\mu_{\text {att }}$ is taken as a constant, the optimal values of $\mu_{\text {att }}, v_{\text {micro }}$, $C_{S t, v o l, 0}$ and $\alpha$ are all in need of determination from the procedure of fitting the simulated $Q-V$ curves to the measured data over all the $\mathrm{NaCl}$ concentrations of interest. The result shows when a nonlinear least square algorithm is used, $\mu_{a t t}=1.18, v_{m i}=0.35 \mathrm{~cm}^{3} / \mathrm{g}$, $\alpha=10.5 \mathrm{~F} \cdot \mathrm{m}^{3} / \mathrm{mol}^{2}$ and $C_{S t, v o l, 0}=2.1 \times 108 \mathrm{~F} / \mathrm{m}^{3}$. These values are in line with those suggested by other works $[30,38,45]$, with a good agreement between the simulated and measured $Q-V$ curves as a result, as shown in Figure 12.

The fact of $v_{m i}=0.35 \mathrm{~cm}^{3} / \mathrm{g}$ suggests that about $90 \%$ of the micropore space is available for counterion adsorption. This is deemed to be much more reasonable than the result ( $\sim 70 \%$ ) of the GCS and MPBS models imply. On the other hand, $C_{S t, v o l, 0}=2.1 \times 10^{8} \mathrm{~F} / \mathrm{m}^{3}$ is equivalent to $\varepsilon_{r}=\sim 7.29$ given a Stern layer thickness on the order of magnitude of hydrated ions of $\mathrm{Na}+$. This is also reasonable, as Booth correction of dielectric permittivity (see Figure 7) suggests. Therefore, the $\mathrm{mD}$ model is physically much more plausible than both GCS and MPBS models. 


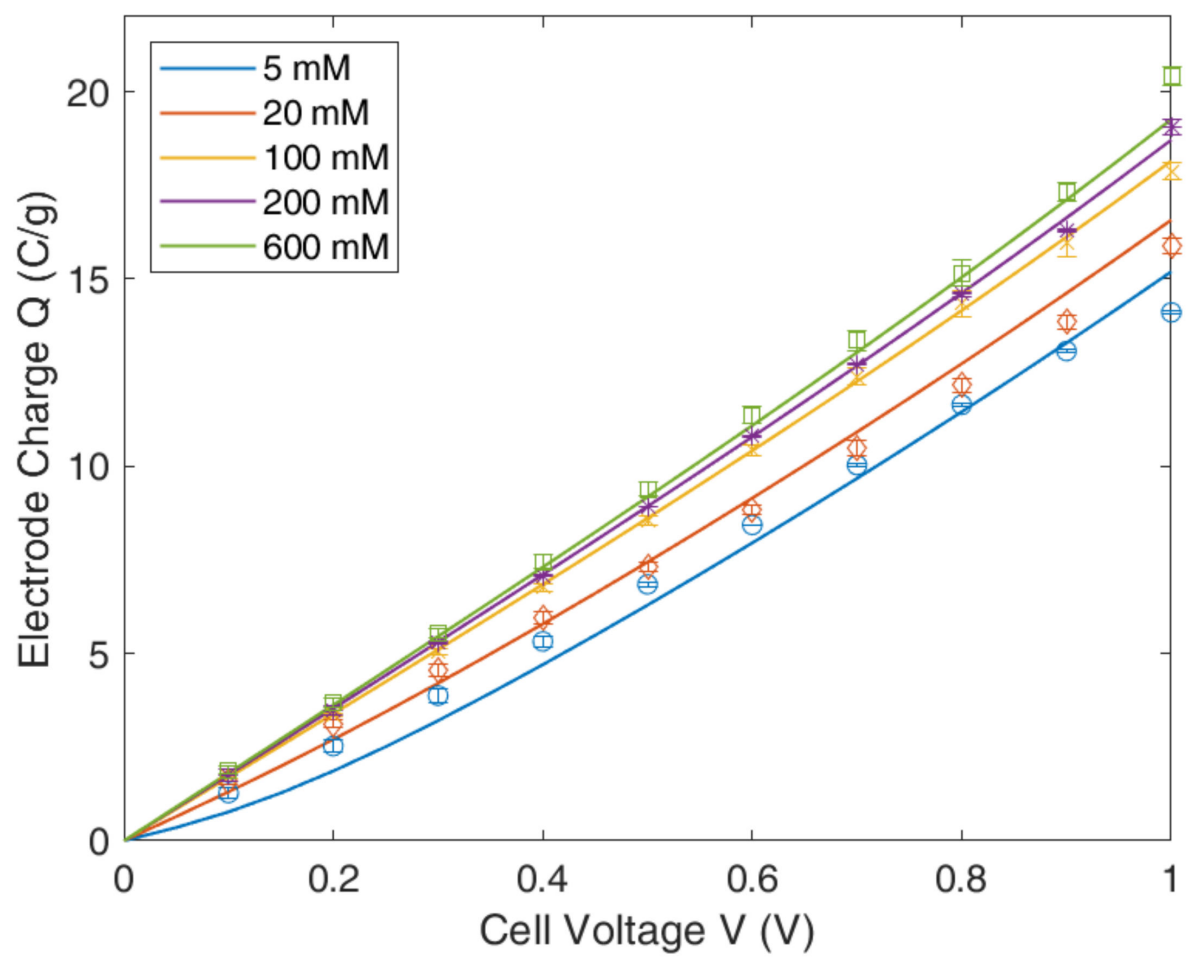

Figure 12. Equilibrium electrode charge $Q$ versus applied voltage $V$ for different values of $\mathrm{NaCl}$ solution. Lines refer to the results of $\mathrm{mD}$ model $\left(a=10.5 \mathrm{~F} \cdot \mathrm{m}^{3} / \mathrm{mol}^{2}, C_{S t, v o l, 0}=2.1 \times 10^{8} \mathrm{~F} / \mathrm{m}^{3}\right.$, $\mu_{\text {att }}=1.18, v_{m i}=0.35 \mathrm{~cm}^{3} / \mathrm{g}$ ), marks refer to the experiment data and error bars of the experimental data are indicated by horizontal lines through the marked data points.

In the improved $\mathrm{mD}(\mathrm{i}-\mathrm{mD})$ model [39], the excess chemical potential, $\mu_{a t t}$ is related to the total concentration of all ions in the micropores as given in Equation (25). The energy parameter E should now be determined a priori, instead of $\mu_{\text {att }}$. Using the same fitting procedure as discussed above, we found that the optimal values of the fitting parameters are: $E=436.7 \mathrm{kT} \mathrm{mol} / \mathrm{m}^{3}, C_{S t, v o l, 0}=2.06 \times 108 \mathrm{~F} / \mathrm{m}^{3}, \alpha=13.6 \mathrm{~F} \cdot \mathrm{m}^{3} / \mathrm{mol}^{2}$ and $v_{m i}=0.364 \mathrm{~cm}^{3} / \mathrm{g}$. The value of $v_{m i}=0.364 \mathrm{~cm}^{3} / \mathrm{g}$ suggests that the availability of micropore volume for storing the counterions is $\sim 94 \%$. $C_{S t, v o l, 0}=2.06 \times 10^{8} \mathrm{~F} / \mathrm{m}^{3}$ corresponding to $\varepsilon_{r}=\sim 7.17$ also implies a reasonable Stern layer thickness. The difference between $\mathrm{mD}$ and i-mD models is, therefore, mainly on the $C_{S t, v o l, 0}$ values. As shown in Figure 13, the decrease of $C_{S t, v o l}$ with increasing volume charge in both mD models follow essentially the same pattern. As a result, $\varepsilon_{r}$ also decreases but only slightly. It becomes $\sim 6.77$ and $\sim 6.49$ at $\rho=1.2 \times 10^{8} \mathrm{C} / \mathrm{m}^{3}$ in the $\mathrm{mD}$ and i-mD model, respectively.

With the optimal parameters, it is seen from Figure 14 that the simulated $Q-V$ curves by $\mathrm{i}-\mathrm{mD}$ model agrees almost entirely with the experimental data, much better than the results of the other models (see Figures 7-12).

To facilitate the comparison of different EDL models, we summarize in Table 2. the physical parameters involved in the models and the optimal values obtained from the fitting procedures. As discussed above, the parameter values of both $\mathrm{mD}$ and i-mD models are not only reasonable but also roughly the same. However, as clearly seen from the results shown in Figures 12 and 14, the i-mD model is superior to the $\mathrm{mD}$ model in reproducing the dependence of $Q$ on $V$ under different electrolyte concentrations. 


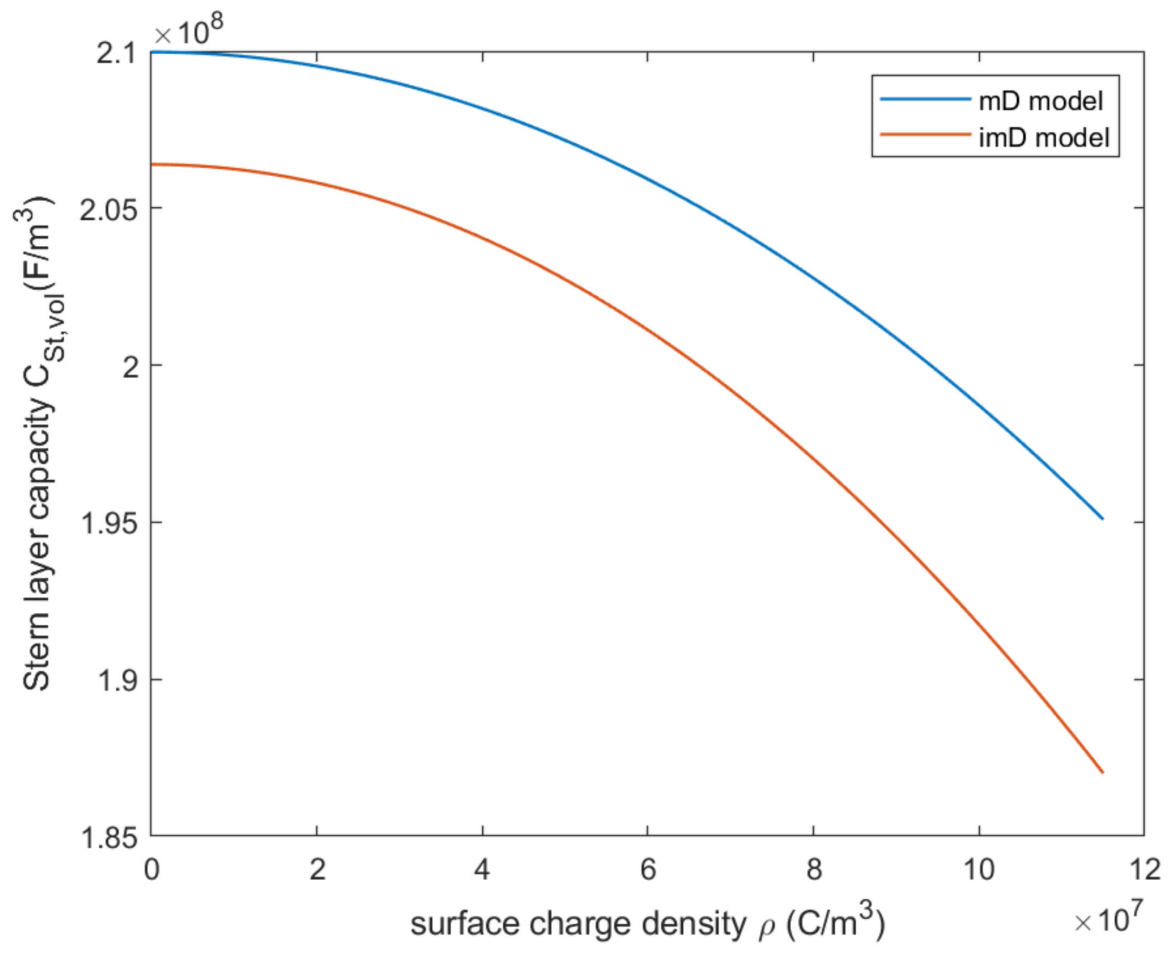

Figure 13. Stern layer capacity $C_{S t, v o l}$ as a function of surface charge density $\rho$.

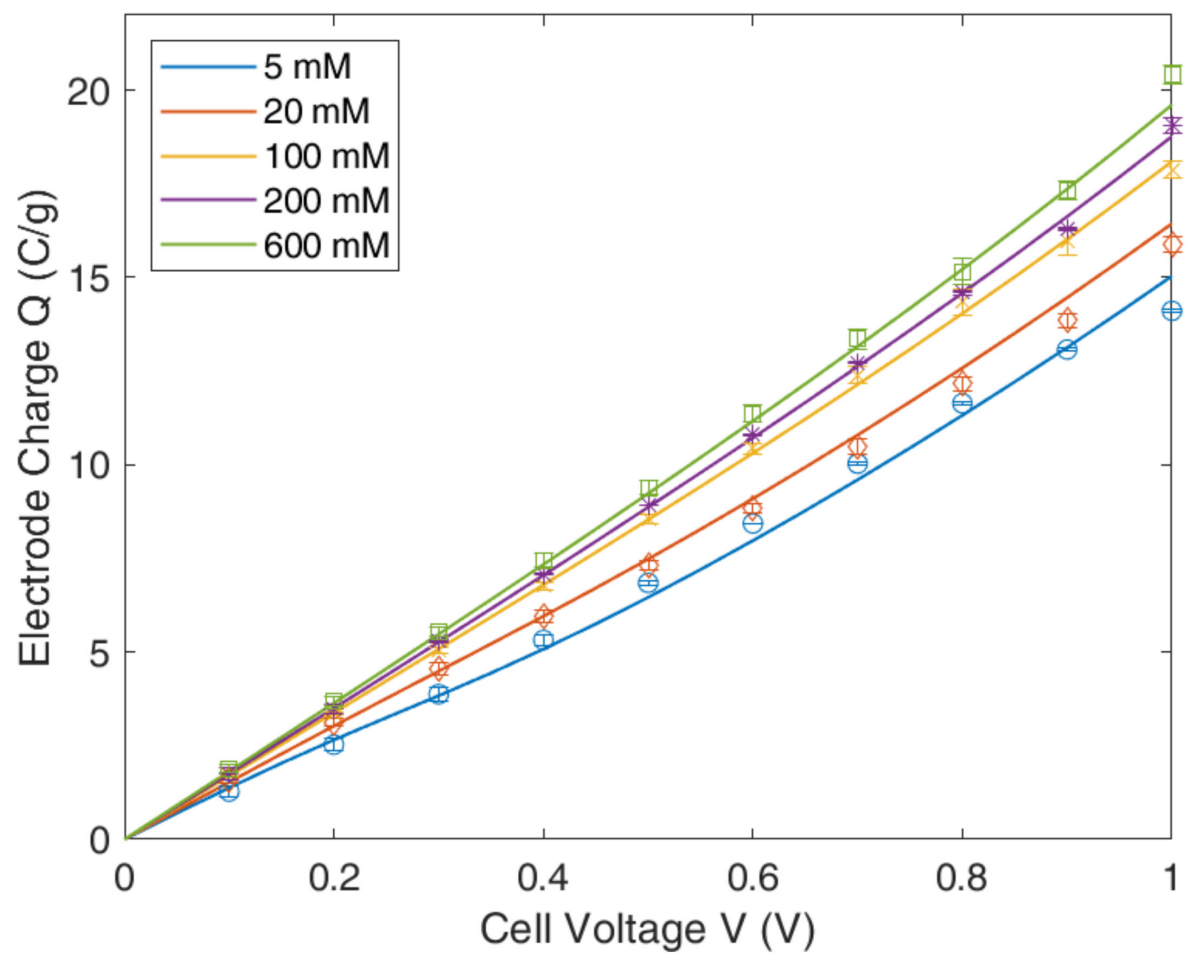

Figure 14. Equilibrium electrode charge $Q$ versus applied voltage $V$ for different values of $\mathrm{NaCl}$ solution. Lines refer to the results of i-mD model $\left(a=13.6 \mathrm{~F} \cdot \mathrm{m}^{3} / \mathrm{mol}^{2}, C_{S t, v o l, 0}=2.06 \times 10^{8} \mathrm{~F} / \mathrm{m}^{3}\right.$, $E=436.7 \mathrm{kT} \mathrm{mol} / \mathrm{m}^{3}, v_{m i}=0.36 \mathrm{~cm}^{3} / \mathrm{g}$ ), marks refer to the experiment data and error bars of the experimental data are indicated by horizontal lines through the marked data points. 
Table 2. Optimal parameters values for different theoretical models in the present paper.

\begin{tabular}{|c|c|c|c|c|c|c|}
\hline \multirow[t]{2}{*}{ Models } & \multicolumn{6}{|c|}{ Parameters } \\
\hline & $\begin{array}{c}C_{s t} \\
\left(\mathrm{~F} / \mathrm{m}^{2}\right)\end{array}$ & $\begin{array}{c}S_{e f f} \\
\left(\mathrm{~m}^{2} / \mathrm{g}\right)\end{array}$ & $\begin{array}{c}\delta \\
(\mathrm{nm})\end{array}$ & $\varepsilon_{r}$ & $\begin{array}{c}d \\
(\mathrm{~nm})\end{array}$ & \\
\hline GCS & 0.131 & 619.46 & 5.3 & 78.5 & - & \\
\hline GCS-B $*$ & $1.0-1.15$ & 540.25 & 4.19 & $68.5-78.5$ & - & \\
\hline MPBS & 0.141 & 580.88 & 4.92 & 78.5 & 0.75 & \\
\hline \multirow[t]{2}{*}{ MPBS-B * } & $0.09-0.095$ & 857.79 & 7.29 & $74.6-78.5$ & 1.42 & \\
\hline & $\begin{array}{l}C_{s t, v o l, 0} \\
\left(\mathbf{F} / \mathbf{m}^{3}\right)\end{array}$ & $\begin{array}{c}\alpha \\
\left(\mathrm{Fm}^{3} / \mathrm{mol}^{2}\right)\end{array}$ & $\begin{array}{l}C_{s t, v o l} \\
\left(\mathbf{F} / \mathbf{m}^{3}\right)\end{array}$ & $\mu_{a t t}$ & $\begin{array}{c}E \\
\left(\mathbf{k T ~} \mathrm{mol} / \mathrm{m}^{3}\right)\end{array}$ & $\begin{array}{c}v_{m i} \\
\left(\mathrm{~cm}^{3} / \mathrm{g}\right)\end{array}$ \\
\hline $\mathrm{mD}$ & $2.1 \times 10^{8}$ & 10.48 & $(2.1-2.24) \times 10^{8}$ & 1.18 & - & 0.35 \\
\hline$i-m D$ & $2.06 \times 10^{8}$ & 13.65 & $(2.06-2.23) \times 10^{8}$ & $0.23-2.76$ & 436.7 & 0.367 \\
\hline
\end{tabular}

*: with Booth correction.

By contrast, the optimal parameters of the GCS and the MPBS models are physically unreasonable, especially about the Stern layer thickness. As seen in Table 2, even the minimum d value of $4.19 \mathrm{~nm}$ is still far greater than the hydrated radius [44] of $\mathrm{Na}^{+}$ions, in contradiction with the physical explanation of the Stern layer. It is mainly this finding that makes us believe the applicability of the GCS and MPBS models is questionable.

\subsection{Full CDLE Experiment}

The extracted energy per gram $W$ in our CDEL experiment is 0.1 to $0.15 \mathrm{~J} / \mathrm{g}$ at an applied voltage ranging from 0.3 to $0.8 \mathrm{~V}$, which is comparable to the relevant reported energy production of other works, i.e., the $W$ ranged from 0.2 to $0.6 \mathrm{~J} / \mathrm{g}$ at an applied voltage ranging from 0.3 to $0.7 \mathrm{~V}$ is reported by $\mathrm{D}$. Brogioli et al. [22], and $W \approx 0.11$ to $0.22 \mathrm{~J} / \mathrm{g}$ at $V_{\text {ext }}=0.4 \mathrm{~V}$ reported by Nasir et al. [18]. The reason for the difference in energy production might be attributed to the different CDLE cell design and electrode materials. Note that the results of $Q$ vs. $V$ obtained in single-pass experiments clearly show that, for a fixed value of $Q$, the reduction in the electrolyte concentration results in higher cell potential. This allows us to extract energy by intermittently exchange seawater and freshwater thorough a CDLE cell. In addition, one may expect that, in a full CDLE cycle, the potential rise $\Delta \mathrm{V}$ at sept 2 and the energy extracted should both increase monotonically with the applied voltage $V_{\text {ext }}$, if the kinetics of the full CDLE cycle is solely controlled by the diffusion of ions within the porous electrodes. However, this not the case. As shown in Figure 15, the experimental results suggest a parabolic curve for both $\Delta V$ and $W$. The potential rise $\Delta V$ increases monotonically until it reaches a maximum value at $V_{\text {ext }}=0.6 \mathrm{~V}$ and then followed with a progressive decay with further increase in $V_{\text {ext }}$. Correspondingly, the energy extracted, $W$, achieves a maximum value at $V_{\text {ext }}=0.6 \mathrm{~V}$. This phenomenon was also observed by Jiménez et al. [24] and Iglesias et al. [17] and explained qualitatively by the MPBS model assuming a spherical geometry of solid carbon particles [24]. Our findings do not, however, support the use of such an MPBS model because the results of single-pass experiments, as shown in Figure 14, clearly indicate that both $\Delta V$ and $W$ should monotonically increase with an increase in the applied voltage. The large deviation between experimental data and theoretical prediction at higher applied voltage suggested that using only the equilibrium double layer model itself is not sufficient to describe the performance of a full CDLE cell. An advanced model as the one developed by Rica et al. [27] is then required to include the effect of advection, mass transfer at the electrode/solution interface, ionic diffusion through the electrodes and build-up of EDLs at the micropore space, etc. This work is now undertaken and will be discussed in detail in the near future. 


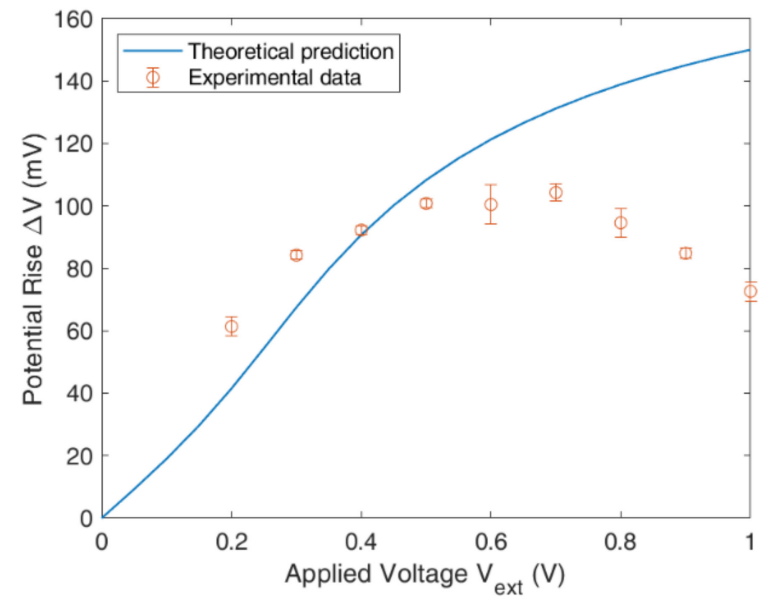

(a)

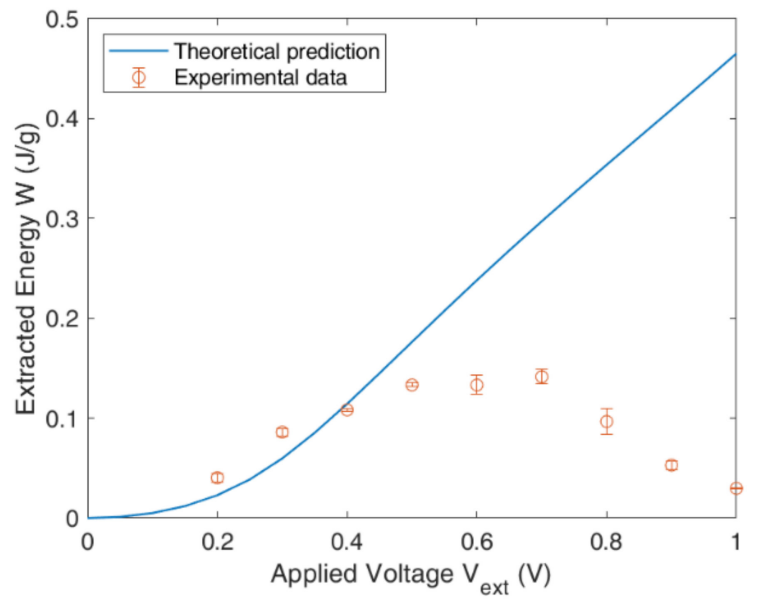

(b)

Figure 15. (a) Potential rise $\Delta V$ in step 2 of CDLE process as a function of cell voltage. (b) Extracted energy of one CDLE cycle at different cell voltage. $R_{\text {ext }}=100 \Omega, c_{\text {fresh }}=20 \mathrm{mM}, c_{\text {sea }}=600 \mathrm{mM}$. The line refers to the theoretical prediction by i-mD model, marks refer to the experiment data and error bars of the experimental data are indicated by horizontal lines through the marked data points.

\section{Conclusions}

In this study, a series of single-pass and full-cycle experiments were performed for a self-made CDLE cell in order to exploit its potential to harvest energy from an intermittent exchange of seawater and freshwater. The focus is, however, on the analysis of different EDL models in describing the structural and thermodynamic properties of EDLs at the micropore scale at equilibrium. The results suggest that both GCS and MPBS models involve physically unmeaningful parameters, despite their ability to well reproduce the $Q-V$ curves (the key performance of the CDLE cell) at different $\mathrm{NaCl}$ concentrations. The reason is, perhaps, that both models were applied on the assumption of thin EDLs, which is unreasonable since $\lambda_{D} \gtrsim H_{p}$ in all the cases of interest. By contrast, both the $\mathrm{mD}$ and i-mD models consider the strong overlap of EDLs within the micropores of the electrodes, making the diffuse potential constant. As a result, the non-ideal properties of the EDLs were well accounted for with only a few parameters that are physically interpretable. In particular, the i-mD model considers the excess chemical potential as a function of the total concentration of $\mathrm{NaCl}$ within the micropores instead of a constant value. This makes i-mD model superior to $\mathrm{mD}$ model in describing the performance of the CDLE cell at equilibrium, and therefore should be recommended to be used in the first place.

However, when applied for practical use, it was found that the theoretical calculation of the i-mD model alone gives inconsistent results with the data of the full-cycle CDLE experiments about the dependence of $\Delta V$ and $W$ on the applied voltage. The model and the single-pass experimental results suggest that both $\Delta V$ and $W$ should increase monotonically with the applied voltage, in contrast to a parabolic behavior that was found experimentally with a maximum of $W$ located at $V_{\text {ext }}=0.6 \mathrm{~V}$. The reason for this difference may be attributed to the higher current leakage and the effect of ion size at larger applied voltage $[18,24,25]$. However, to understand the performance of the full-cycle CDLE cells better, an advanced model is expected to include the effect of advection, mass transfer at the electrode/solution interface, ionic diffusion through the electrodes and i-mD description of EDLs at the micropore space, etc. Thus, the knowledge we obtained from this study provides important guidance towards the application of EDL models in CDLE technology.

Author Contributions: Writing—original draft preparation, Z.Z.; writing—review and editing, L.L.; methodology, Z.Z.; data curation, X.B.; simulation, S.M.; supervision, Y.L. All authors have read and agreed to the published version of the manuscript. 
Funding: This research was funded by Swedish Energy Agency (Energimyndigheten), Sweden, project number 44606-1.

Institutional Review Board Statement: Not applicable.

Informed Consent Statement: Not applicable.

Data Availability Statement: Not applicable.

Acknowledgments: Zhi Zou acknowledges the financial support from China Scholarship Council (CSC).

Conflicts of Interest: The authors declare no conflict of interest.

\section{Nomenclature}

CapMix Capacitive mixing

CDP Capacitive energy extraction based on Donnan Potential

CDLE Capacitive energy extraction based on Double Layer Expansion

SE Soft Electrode

EDL Electric double layer

PB Poisson Boltzmann

GCS Gouy-Chapman-Stern

MPBS Modified Poisson-Boltzmann-Stern

$\mathrm{mD} \quad$ modified Donnan

$S_{B E T} \quad$ Specific surface area

$S_{\text {micro }} \quad$ Microporous surface area measurement

$V_{\text {tot }} \quad$ Total volume of pores

$H_{p} \quad$ Pore thickness

$D_{B J H} \quad$ Average pore diameter

$Q \quad$ Equilibrium electrode charge per mass, $\mathrm{C} / \mathrm{g}$

I Electric current, A

Imea $\quad$ Measured current, A

$I_{\text {lea }} \quad$ Leakage current, A

$m_{\text {elec }} \quad$ Mass of total electrodes, $\mathrm{g}$

$V_{\text {ext }} \quad$ Applied voltage, $\mathrm{V}$

$V \quad$ Cell potential, $\mathrm{V}$

$\times V \quad$ Potential increase due to the double layer expansion, $\mathrm{V}$

$R_{\text {ext }} \quad$ External resistance, $\Omega$

$W \quad$ Extracted energy, $\mathrm{J} / \mathrm{g}$

c Electrolyte concentration, $\mathrm{mm}$

$c_{\text {fresh }} \quad$ Electrolyte concentration of freshwater, $\mathrm{mol} / \mathrm{m}^{3}$

$c_{\text {sea }} \quad$ Electrolyte concentration of seawater, $\mathrm{mol} / \mathrm{m}^{3}$

$c_{\text {ions }, m i}$ micropore total ion concentration, $\mathrm{mol} / \mathrm{m}^{3}$

$n_{i} \quad$ number concentration of the $i$ th species in diffuse layer, $1 / \mathrm{m}^{3}$

$n_{i, \infty} \quad$ number concentration of the $i$ th species at the bulk solution, $1 / \mathrm{m}^{3}$

$n_{i, m i} \quad$ number concentration of $i$ th species in the micropores of the electrode, $1 / \mathrm{m}^{3}$

$e \quad$ elementary charge, $\mathrm{C}$

$z_{i} \quad$ valence of the $i$ th species

$k_{B} \quad$ Boltzmann constant, $\mathrm{J} / \mathrm{K}$

$\varepsilon_{0} \quad$ free space permittivity, $\mathrm{F} / \mathrm{m}$

$\varepsilon_{r} \quad$ relative permittivity of the electrolyte solutions

$\psi \quad$ electric potential, $\mathrm{V}$

$\psi_{s} \quad$ surface potential, $\mathrm{V}$

$\Delta \psi_{S t} \quad$ electric potential drop across the stern layer, $\mathrm{V}$

$\Delta \psi_{d} \quad$ electric potential difference across the diffuse layer, $\mathrm{V}$ 


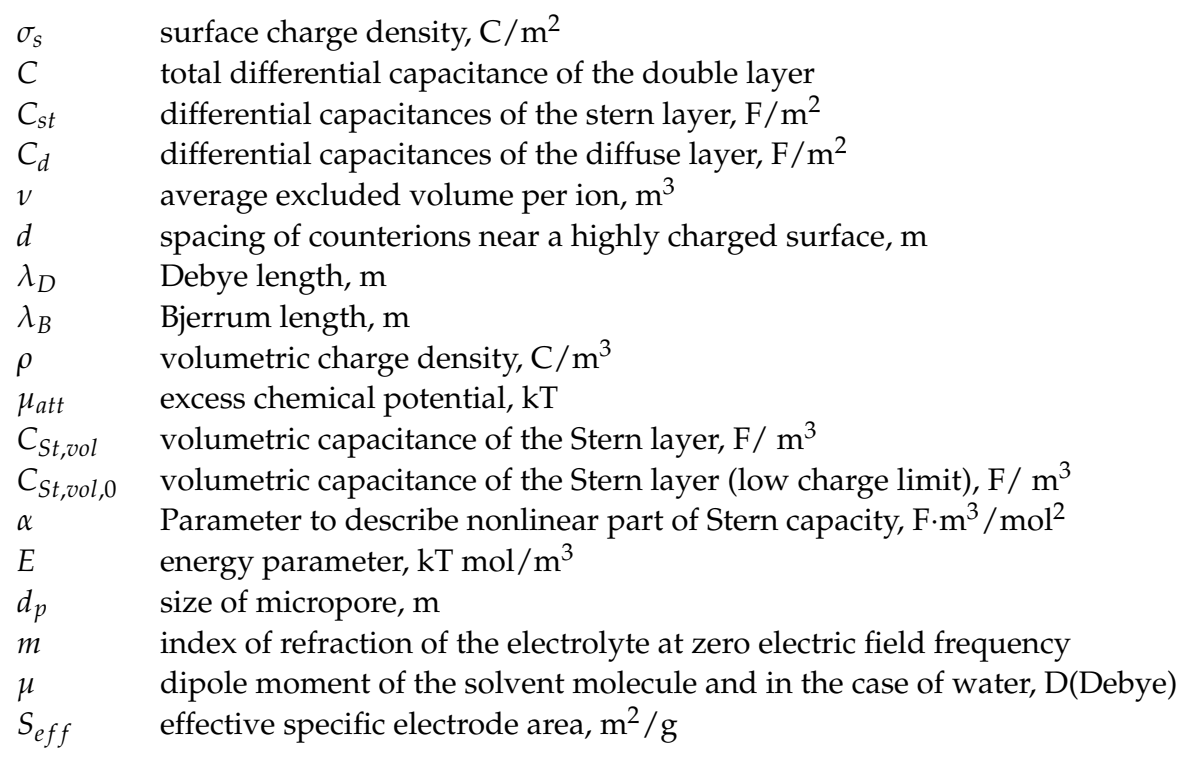

\section{References}

1. Shirzad, M.; Karimi, M.; Abolghasemi, H. Polymer inclusion membranes with dinonylnaphthalene sulfonic acid as ion carrier for Co(II) transport from model solutions. Desalin. Water Treat. 2019, 144, 185-200. [CrossRef]

2. De Medeiros, A.D.M.; da Silva, C.J.G.; de Amorim, J.D.P.; do Nascimento, H.A.; Converti, A.; Costa, A.F.D.; Sarubbo, L.A Biocellulose for Treatment of Wastewaters Generated by Energy Consuming Industries: A Review. Energies 2021, $14,5066$. [CrossRef]

3. Ozcan, H.G.; Hepbasli, A.; Abusoglu, A.; Anvari-Moghaddam, A. Advanced Exergy Analysis of Waste-Based District Heating Options through Case Studies. Energies 2021, 14, 4766. [CrossRef]

4. Pattle, R. Production of electric power by mixing fresh and salt water in the hydroelectric pile. Nature 1954, 174, 660. [CrossRef]

5. Boon, N.; van Roij, R. 'Blue energy' from ion adsorption and electrode charging in sea and river water. Mol. Phys. 2011, 109, 1229-1241. [CrossRef]

6. $\quad$ Post, J.W.; Hamelers, H.V.M.; Buisman, C.J.N. Energy recovery from controlled mixing salt and fresh water with a reverse electrodialysis system. Environ. Sci. Technol. 2008, 42, 5785-5790. [CrossRef]

7. Achilli, A.; Childress, A.E. Pressure retarded osmosis: From the vision of Sidney Loeb to the first prototype installation. Desalination 2010, 261, 205-211. [CrossRef]

8. Loeb, S. Osmotic Power-Plants. Science 1975, 189, 654-655. [CrossRef]

9. Weinstein, J.N.; Leitz, F.B. Electric power from differences in salinity: The dialytic battery. Science 1976, 191, 557-559. [CrossRef]

10. Yip, N.Y.; Elimelech, M. Comparison of energy efficiency and power density in pressure retarded osmosis and reverse electrodialysis. Environ. Sci. Technol. 2014, 48, 11002-11012. [CrossRef]

11. Yip, N.Y.; Brogioli, D.; Hamelers, H.V.M.; Nijmeijer, K. Salinity Gradients for Sustainable Energy: Primer, Progress, and Prospects Environ. Sci. Technol. 2016, 50, 12072-12094. [CrossRef] [PubMed]

12. Kim, T.; Rahimi, M.; Logan, B.E.; Gorski, C.A. Harvesting Energy from Salinity Differences Using Battery Electrodes in a Concentration Flow Cell. Environ. Sci. Technol. 2016, 50, 9791-9797. [CrossRef]

13. Brogioli, D. Extracting Renewable Energy from a Salinity Difference Using a Capacitor. Phys. Rev. Lett. 2009, 103, 058501. [CrossRef]

14. Sales, B.B.; Saakes, M.; Post, J.W.; Buisman, C.J.N.; Biesheuvel, P.M.; Hamelers, H.V.M. Direct Power Production from a Water Salinity Difference in a Membrane-Modified Supercapacitor Flow Cell. Environ. Sci. Technol. 2010, 44, 5661-5665. [CrossRef] [PubMed]

15. La Mantia, F.; Pasta, M.; Deshazer, H.D.; Logan, B.E.; Cui, Y. Batteries for Efficient Energy Extraction from a Water Salinity Difference. Nano Lett. 2011, 11, 1810-1813. [CrossRef]

16. Ahualli, S.; Jimenez, M.L.; Fernandez, M.M.; Iglesias, G.; Brogioli, D.; Delgado, A.V. Polyelectrolyte-coated carbons used in the generation of blue energy from salinity differences. Phys. Chem. Chem. Phys. 2014, 16, 25241-25246. [CrossRef] [PubMed]

17. Iglesias, G.R.; Fernandez, M.M.; Ahualli, S.; Jimenez, M.L.; Kozynchenko, O.P.; Delgado, A.V. Materials selection for optimum energy production by double layer expansion methods. J. Power Sources 2014, 261, 371-377. [CrossRef]

18. Nasir, M.; Nakanishi, Y.; Patmonoaji, A.; Suekane, T. Effects of porous electrode pore size and operating flow rate on the energy production of capacitive energy extraction. Renew. Energy 2020, 155, 278-285. [CrossRef]

19. Iglesias, G.R.; Ahualli, S.; Fernandez, M.M.; Jimenez, M.L.; Delgado, A.V. Stacking of capacitive cells for electrical energy production by salinity exchange. J. Power Sources 2016, 318, 283-290. [CrossRef]

20. Ahualli, S.; Fernandez, M.M.; Iglesias, G.; Delgado, A.V.; Jimenez, M.L. Temperature Effects on Energy Production by Salinity Exchange. Environ. Sci. Technol. 2014, 48, 12378-12385. [CrossRef] [PubMed] 
21. Zhao, R.; Biesheuvel, P.M.; Miedema, H.; Bruning, H.; van der Wal, A. Charge Efficiency: A Functional Tool to Probe the Double-Layer Structure Inside of Porous Electrodes and Application in the Modeling of Capacitive Deionization. J. Phys. Chem. Lett. 2010, 1, 205-210. [CrossRef]

22. Brogioli, D.; Zhao, R.; Biesheuvel, P.M. A prototype cell for extracting energy from a water salinity difference by means of double layer expansion in nanoporous carbon electrodes. Energy Environ. Sci. 2011, 4, 772-777. [CrossRef]

23. Brogioli, D.; Ziano, R.; Rica, R.A.; Salerno, D.; Kozynchenko, O.; Hamelers, H.V.M.; Mantegazza, F. Exploiting the spontaneous potential of the electrodes used in the capacitive mixing technique for the extraction of energy from salinity difference. Energy Environ. Sci. 2012, 5, 9870-9880. [CrossRef]

24. Jimenez, M.L.; Fernandez, M.M.; Ahualli, S.; Iglesias, G.; Delgado, A.V. Predictions of the maximum energy extracted from salinity exchange inside porous electrodes. J. Colloid Interface Sci. 2013, 402, 340-349. [CrossRef]

25. Fernandez, M.M.; Ahualli, S.; Iglesias, G.R.; Gonzalez-Caballero, F.; Delgado, A.V.; Jimenez, M.L. Multi-ionic effects on energy production based on double layer expansion by salinity exchange. J. Colloid Interface Sci. 2015, 446, 335-344. [CrossRef]

26. Rica, R.A.; Ziano, R.; Salerno, D.; Mantegazza, F.; Bazant, M.Z.; Brogioli, D. Electro-diffusion of ions in porous electrodes for capacitive extraction of renewable energy from salinity differences. Electrochim. Acta 2013, 92, 304-314. [CrossRef]

27. Rica, R.A.; Brogioli, D.; Ziano, R.; Salerno, D.; Mantegazza, F. Ions Transport and Adsorption Mechanisms in Porous Electrodes During Capacitive-Mixing Double Layer Expansion (CDLE). J. Phys. Chem. C 2012, 116, 16934-16938. [CrossRef]

28. Biesheuvel, P.M.; Bazant, M.Z. Nonlinear dynamics of capacitive charging and desalination by porous electrodes. Phys. Rev. E 2010, 81, 031502. [CrossRef]

29. Porada, S.; Bryjak, M.; van der Wal, A.; Biesheuvel, P.M. Effect of electrode thickness variation on operation of capacitive deionization. Electrochim. Acta 2012, 75, 148-156. [CrossRef]

30. Porada, S.; Borchardt, L.; Oschatz, M.; Bryjak, M.; Atchison, J.S.; Keesman, K.J.; Kaskel, S.; Biesheuvel, P.M.; Presser, V. Direct prediction of the desalination performance of porous carbon electrodes for capacitive deionization. Energy Environ. Sci. 2013, 6, 3700-3712. [CrossRef]

31. Porada, S.; Zhao, R.; van der Wal, A.; Presser, V.; Biesheuvel, P.M. Review on the science and technology of water desalination by capacitive deionization. Prog. Mater. Sci. 2013, 58, 1388-1442. [CrossRef]

32. Bazant, M.Z.; Chu, K.T.; Bayly, B.J. Current-voltage relations for electrochemical thin films. Siam J. Appl. Math. 2005, 65, 1463-1484. [CrossRef]

33. Wang, H.N.; Varghese, J.; Pilon, L. Simulation of electric double layer capacitors with mesoporous electrodes: Effects of morphology and electrolyte permittivity. Electrochim. Acta 2011, 56, 6189-6197. [CrossRef]

34. Biesheuvel, P.M. Thermodynamic cycle analysis for capacitive deionization. J. Colloid Interface Sci. 2009, 332, 258-264. [CrossRef]

35. Biesheuvel, P.M.; van Soestbergen, M. Counterion volume effects in mixed electrical double layers. J. Colloid Interface Sci. 2007, 316, 490-499. [CrossRef] [PubMed]

36. Kilic, M.S.; Bazant, M.Z.; Ajdari, A. Steric effects in the dynamics of electrolytes at large applied voltages. I. Double-layer charging. Phys. Rev. E 2007, 75, 021502. [CrossRef]

37. Biesheuvel, P.M.; Zhao, R.; Porada, S.; van der Wal, A. Theory of membrane capacitive deionization including the effect of the electrode pore space. J. Colloid Interface Sci. 2011, 360, 239-248. [CrossRef]

38. Porada, S.; Weinstein, L.; Dash, R.; van der Wal, A.; Bryjak, M.; Gogotsi, Y.; Biesheuvel, P.M. Water Desalination Using Capacitive Deionization with Microporous Carbon Electrodes. ACS Appl. Mater. Inter. 2012, 4, 1194-1199. [CrossRef]

39. Biesheuvel, P.M.; Porada, S.; Levi, M.; Bazant, M.Z. Attractive forces in microporous carbon electrodes for capacitive deionization. J. Solid State Electr. 2014, 18, 1365-1376. [CrossRef]

40. Wang, H.N.; Pilon, L. Accurate Simulations of Electric Double Layer Capacitance of Ultramicroelectrodes. J. Phys. Chem. C 2011, 115, 16711-16719. [CrossRef]

41. Booth, F. The dielectric constant of water and the saturation effect. J. Chem. Phys. 1951, 19, 391-394. [CrossRef]

42. Booth, F. Dielectric constant of polar liquids at high field strengths. J. Chem. Phys. 1955, 23, 453-457. [CrossRef]

43. Basu, S.; Sharma, M.M. Effect of Dielectric Saturation on Disjoining Pressure in Thin-Films of Aqueous-Electrolytes. J. Colloid Interface Sci. 1994, 165, 355-366. [CrossRef]

44. Tansel, B.; Sager, J.; Rector, T.; Garland, J.; Strayer, R.F.; Levine, L.F.; Roberts, M.; Hummerick, M.; Bauer, J. Significance of hydrated radius and hydration shells on ionic permeability during nanofiltration in dead end and cross flow modes. Sep. Purif. Technol. 2006, 51, 40-47. [CrossRef]

45. Zhao, R.; van Soestbergen, M.; Rijnaarts, H.H.M.; van der Wal, A.; Bazant, M.Z.; Biesheuvel, P.M. Time-dependent ion selectivity in capacitive charging of porous electrodes. J. Colloid Interface Sci. 2012, 384, 38-44. [CrossRef] 